\begin{tabular}{|c|}
\hline مجلة الخدمة الاجتماعية \\
\hline
\end{tabular} 
لاثكك أن ظاهرة الارهاب من الظواهر قديمة الظهور بالمجتمعات الانسانية ، والمتعددة العواملالتي تؤدى الى وجودها فى تلك المتمعات ،ما بين العوامل الاجتماعية والاقتصادية

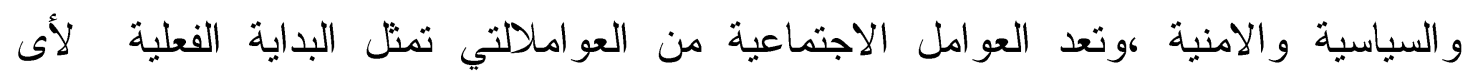
انحراف عامة ،و الارهاب خاصة ، ومن أبرزالعوامل الاجتماعية وجودا فى المجتمعات

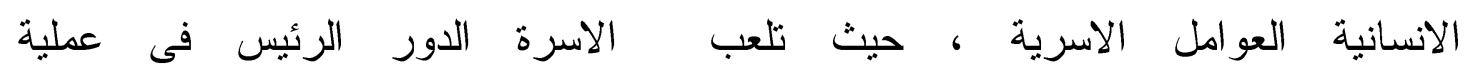
التنشئةالاجتماعيتلأفر ادفى المجتمع رغم تعدد المؤسسات التي اصبحت تشاركها هذا الدور حاليا ، فى ظل المتغيرات التكنولوجيةو المعلوماتبةالجديدة ، و هذا بدوره اضفى الأهيةالكبيرة على اللبنة الاولى للمجتمع فى اكتساب افرادها القيمالتربوية الهامه ، لذلك أي خلل يحدث لدور هالوظيفي، تظهر نتائجه السلبية على الافراد فى محيط المجتمع عامه ،و الأسرة خاصه، الهئ

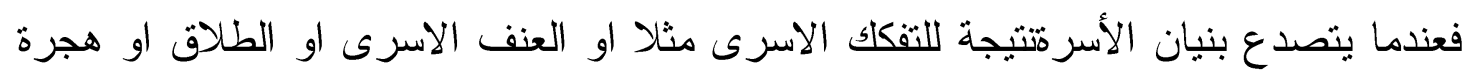

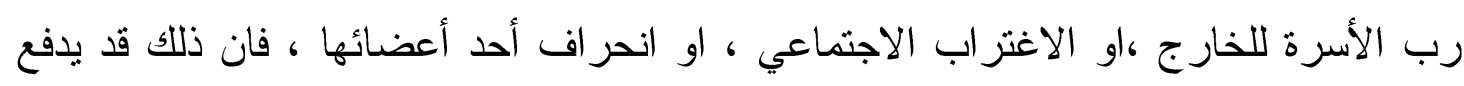

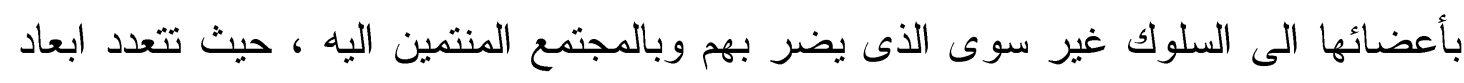

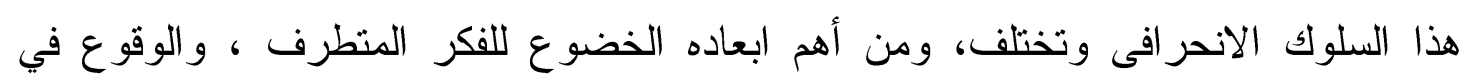

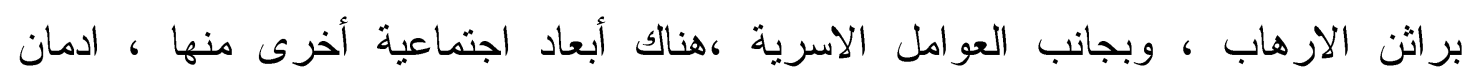

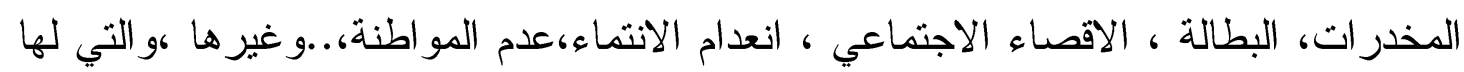
دور هام في وجود ظاهرة الارهاب بالمجتمع المصري.

حيث اضحى الارهاب ظاهره اجتماعيه عالميه لا يخلو منها أي مجتمع باختلاف انتماءاتهالسياسيةو الدينية، ولها الكثير من المخاطر الجسيمةعلى المجتمع، وذلك بما ينتج عنه لهابه

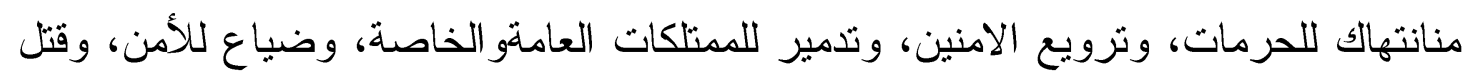
وخطف الافر اد، وتهديد للحياة بصفه عامه.

ورغم ان ظاهرة الارهاب لبست بالجديدة على المجتمعات الإنسانية الا انها باتت جليه وو اضحةفي اواخر النصف الاول من القرن العشرين وتحديدا بعد الحرب العالميةالثانية، حيث ذاق العالم مرارة الحروب الطاحنةالتياتسعت رقعتها وكثرت ضحاياها، حيث هدفت بعض 
الدول الى ترويج الارهاب لتحقيق اهدافها المختلفة فى الدول التي كانت تهيمن عليها في الفتز ات الاستعمارية السابقة.

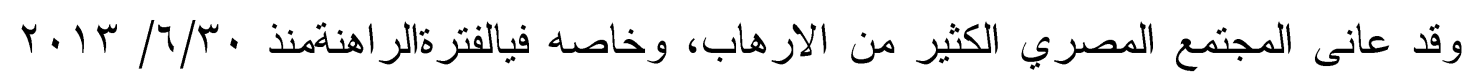
حيث اضحى الارهاب من الظواهر الاجتماعية الإجرامية التي تهدد الامن القومي ، وتهدد

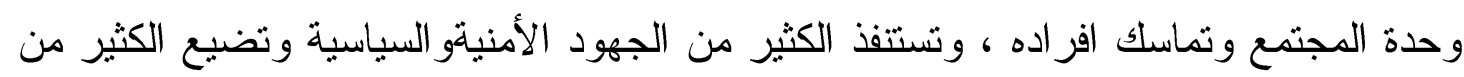
الجهود التتموية والمقدرات الماليةالتي تخصص لمحاربة هذه الظاهرثفي المجتمع المصري كوقد تتاولها الكثير من الباحثين و المتخصصين بالدراسة و التحليل للوقوف على حقيقة هذه الظاهرةفي المجتمع المصري حيث تتاولوا ذلك اما عن طريق الكتب او الابحاث المتتوعة، سواء الورقية منها او الإككترونية ، لذلك كان للصحافة الإككترونية دور في نوضيح الحقيقة الاجتماعية لظاهرة الارهاب ، حيث تعد الصحافة الإلكترونية اداه هامه في تطوير المجتمعات اعلاميا وثقافيا ، ووسيله فعاله في نشر الوعى بين افراد المجتمع بطريقه مشوقه وسريعفةي ظل المتغير ات العالمية والتكنولوجية الحالية، كما لها دور فعال في معالجة الكثير من القضايا التي تهدد الامن القوميالمصري ، وعلى راسها ظاهرة الارهاب بأبعادها الاجتماعية

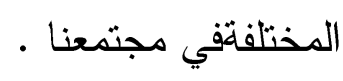
مشكلة البحث :-

نظر اللأهميةا لكبيرة للصحافة الإلكترونية في نشر الافكار المختلفة والوعي الثقافي بين افراد

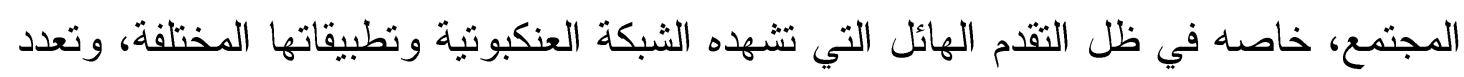
مواقع التواصل الاجتماعي، والمواقع الإلكترونية الإخبارية، والاقبال الكبير لرواد الانترنت على مثل هذه المواقع الإخبارية حيث تثميز بسرعه في نشر الخبر، و التعليق عليه، واتساع مساحة التأثير على الافز اد او التخذية العكسية للرسالة.

ومن ثم تكمن مشكلة البحث في ابراز القصور الملاحظ للعو امل الاجتماعية التي تؤدى للجوء الافراد الى الانضمام للجماعات الإزهابية المختلفة ، وعليه كانت الضرورة فى توضيح هذه العوامل الاجتماعية المختلفة لظاهرة الارهاب في المجتمع المصريفي الفترة الحالية التي 
تناولتها الصحف الإلكترونية المختلفة ،خاصه لما تتسم به هذه الفترة بعد •r/T/ ا • بمن خصوصيه كبيره في الحياه الاجتماعية والاقتصادية و السياسية في المجتمع المصري.

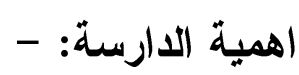

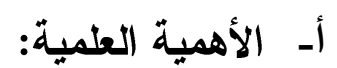

- تتمثل في محاولة الرصد و التحليل العلمي لأكثر العو املالاجتماعية التي قد تؤدى الى

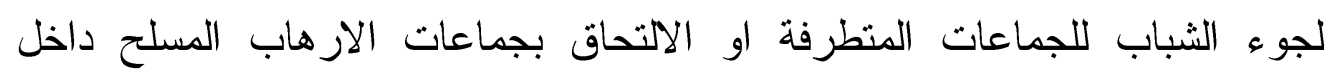
وخارج الوطن، وذلك للتوصل لمجموعة نتائج علمية تفيد في اعادة وبناء الشخصية الثبابية القويةقفيالمجتمعالمصري.

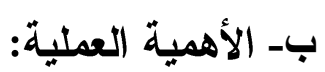

- - تكمن في توعية القائمين على الامر في المجتمع فيالنواحيالأمنيةو السياسيةفي المجتمع المصري الى العواملالاجتماعية، ودورها في تماسك المجتمع،ودورها

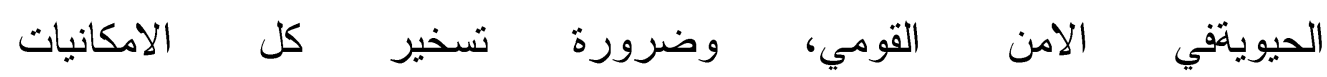
الاجتماعيةو الاقتصاديةو السياسية للمجتمع للتقليل منالقصور للمؤسسات التي تئدى هذه

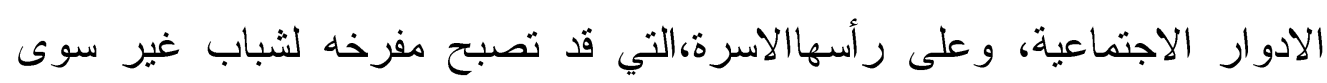
اجتماعيا يسهل وقو عهفي الارهاب بأشكالهالمختلفة. مبررات اختيار موضوع الاراسة: -

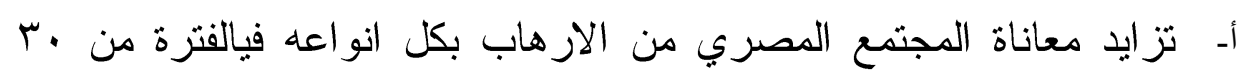

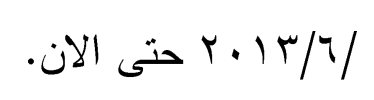

ب- الاقبال الثديد على قراءة، وتصفح الانترنت من خلال الصحافة الإكترونية التي اصبحت وسيلة سهله، وسريعة لمعرفة الاخبار.

ج- تز ايد استقطاب الثباب الذييعاني من مشاكل وازمات اجتماعيه لجماعات الفكر المتطرف والارهاب بكل أثكاله. 
د- اهمال العوامل الاجتماعية من قبل صناع القزار، ودورها في لجوء اهواء

الثباب للاندماج في الجماعات الإرهابية، على عكس اهتمامهم بالعوامل السياسية والأمنية في المجتمع المصري.

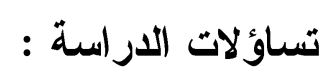

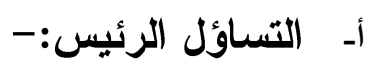

- كيف تتاولت الصحف الإكترونية|المصرية|العو امل الاجتماعية لظاهرة الارهاب

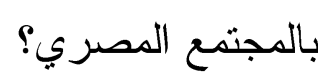

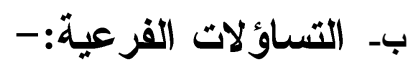
- ما أهم العو املالاجتماعية لظاهرة الارهاب فى المجتمع المصري؟ - ما مدى وعى صناع القرار بدور العواملالاجتماعيةفى وجود ظاهرة الارهاب فى

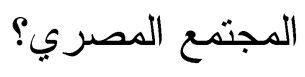
- ما مدى تركيز الصحف الإكترونية على العواملالاجتماعية للإزهاب دون غيرها

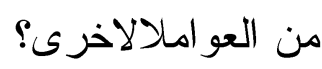

- كيف يرى المثقفون و المتخصصون هقيقة العواملالاجتماعيةعامةوالأسرية خاصةلظاهرة الارهاب فى الصحف الإكترونية؟

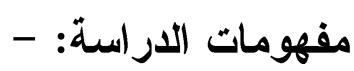

\section{• الارهاب:-Terrorism}

الارهاب من أكثر المفهومات المرتبطة بالأمنالقوميفى معظم الدراسات و العلمية ، وعلية يجب تعريف الامن لنستطيع التعرف على المفهوم الحققيلإزهاب ،وفي إطار هذه الحقيقة يكون المفهوم الثامل "للأمن" من وجهة نظر علمية هو "القدرة التي تتمكن بها الدولة من تأمين

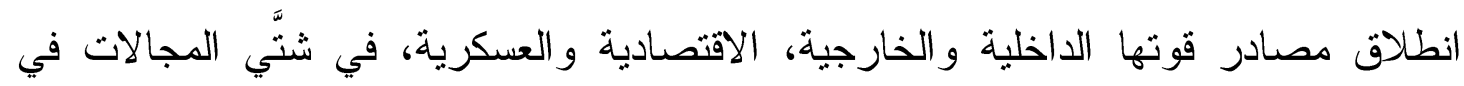
مواجهة المصادر التي تهددها في الداخل والخارج، في السلم وفي الحرب، مع استمرار 
الانطلاق المؤمَّن لتلك القوى في الحاضر و المستقبل تخطيطاً للأهداف المخططة(حسين l) (1) Th 10

وعلية نتعرف على الارهاب كفهوم ظهر مع بداية البشر توارثه جيلا بعد جيل فمنذ الخليقة

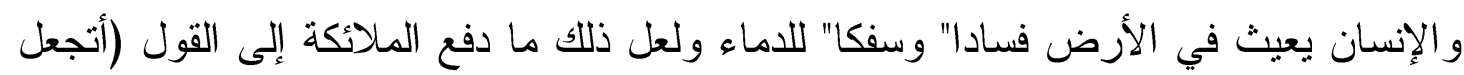
فيها من يفسد فيها ويسفك الدماء ونحن نسبح بحمدك ونقس للك) (الاية.ب سورة البقرة) صدق اله العظيم ، والإزهاب بمعناه الحديث فلم يظهر إلا في المجازر التي أعقبت الثورة الفرنسية ،وظهر موضوع الارهاب المعاصر جليا بعد الحرب العالمية الثانية ، وخلال هذه الفترة تنوع الارهاب واختلفت اساليبه فهناك الارهاب الداخلي الذي جرمته القوانين الداخليةالوضعية، وهناك ارهاب الدولة الذي تباشره الدول وهناك ارهاب الجماعات

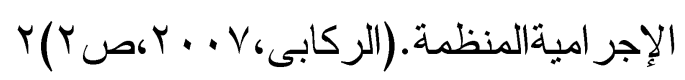

ومعظم الناس لديهم فكرة أو انطباع غامض عن ما هو الإرهاب، حيث تفتقر الكلمة إلى الدقة الملموسة و الى تعريف توضيحي لها. BRUCE HOFFMAN.2015.p2) 3)

فالإرهاب لغة يعني: العمل الذي يُحدث الإخافة، والفزع، و الذعر،والإرهابي هو الذييُحدث الخوف و الفزع و الذعر عند الآخرين، بعمل مفزع ومخيف ، قال ابن منظور في كتابه " لسان

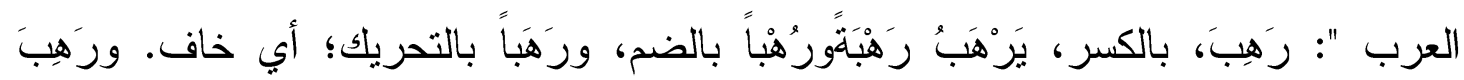

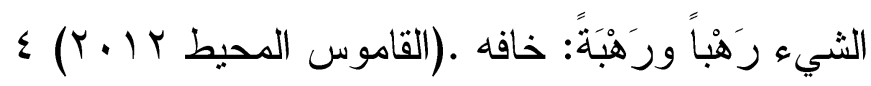
و الإر هاب في الثر ع:ينقسمقسمان :

اولا: قسم مذهوم ، ويحرم فعله وممارسته وهو من كبائر الذنوب ويستحق مرتكبه العقوبة و الذم وهو يكون على مستوى الدول والجماعات والأفراد وحقيقته الاعتداء على الآمنين بالسطو من قبل دول مجرمة أو عصابات أو أفراد بسلب الأموال و الممتلكات و الاعتداء على الحرمات و إخافة الطرق خارج المدن و التسلط على الشعوب من قبل الحكام الظلمة من كبت الحريات وتكميم الأفو اهونحو ذلك .

ثانيا : إرهاب مشروع ، شرعه الله لنا وأمرنا به وهو إعداد القوة والتأهب لمقاومة أعداء الله ورسوله قال تعالى ( وأعدوا لهم ما استطعتم من قوة ومن رباط الخيل ترهبون به عدو الله 
و عدوكم وآخرين من دونهم لا تعلمونهم الله يعلمه ) (الآية .7 سورة الانفال ) فهذه الآية الكريمة نص في أنه يجب على المسلمين أن يبذلو ا قصارى جهدهم في التسليح و إعداد القوة

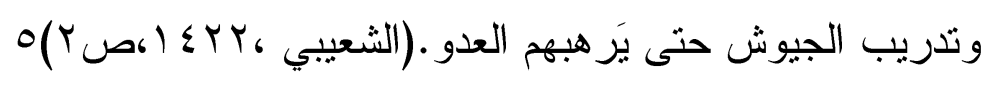

- و الإرهاب يشكل تهديدا رئيسيا للسلام و الأمن الدوليين ويقوض القيم الأساسية للأمم المتحدة، وبالإضافة إلى التكلفة البشرية المدمرة للإز هاب، من حيث الأرواح التي فقدت، و دائمة تهدف

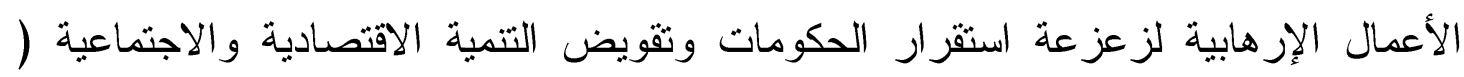
T( UNODC .2015.p1

وعرفت اتفاقية جنيف الخاصة بمنع وقمع الإرهاب لعام Vاa أبأنه "الأعمال الإجرامية

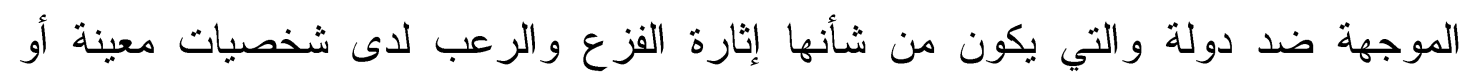
جماعات من أناس أو لاى الجمهور". وعرفته الاتفاقية العربية لمكافحة الإرهاب فى الفقرة

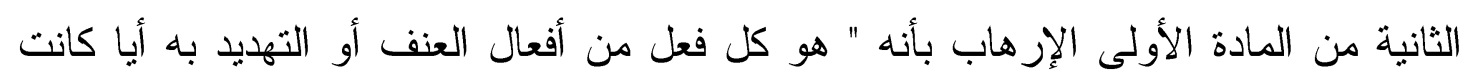

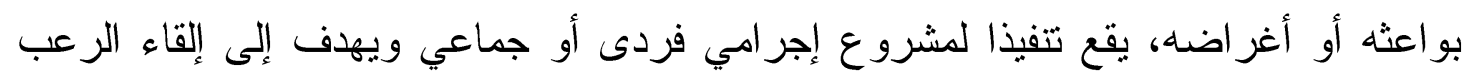
بين الناس أو حريتهم أو أمنهم للخطر أو إلحاق الضرر بالبيئة أو بإحدى المر افق أو الأملاك العامة أو الخاصة أو احتلالها أو الاستيلاء عليها أو تعرض أو أحد الموارد الوطنية

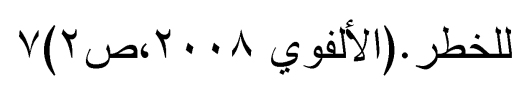

و التعريف القانوني للإزهابيعنى استعمال العنف ضد المدنيين، بهدف تحقيق مآرب سياسية أو

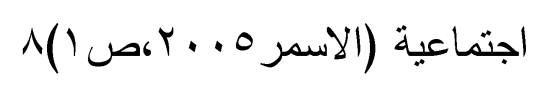

وعرف أخر الارهاب بأنه ظاهرة توجد فى كل المجتمعات الانسانية ويأخذأشكالا متعددة منها:

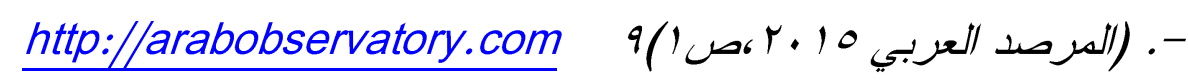
ا -الإرهاب الفردي:وهو فعل برتكبه الفرد لأسباب عديدة هنها:

- الحصول على المبتغى بشكل يتعارض مع القانون أو المفاهيم الاجتماعية السائدة - أسباب دينية أو مذهبية، ضمناً فتاوي ما يسمى “شيو خ” - ويتخذ الإرهاب الفردي أشكالاً متعددة منها: 
- الإرهاب الفكري، الضغط النفسي، التسفيه و التحقير،القذف، العنف الجسدي، التكفير الفردي أو الجماعي، الإفتاء بهدر دم إنسان أو جماعة أو طائفة، القتل الجنائي ضهناً ما يسمى جرائم الشرف

ץ-الإرهاب الجماعي الغير المنظم: وتقوم به عصابات غير منظمة لتحقيق مآرب خاصة تربط عادة بالأسباب التالية، أعمال التخريب و النهب و السطو المسلح، أسباب دينية أو مذهبية مثل بروز بعض الجماعات الإسلامية في كل من تونس وليبيا ومصر وسوريا والعراق، وتتخذ ممارساتها الإزهابية الاشكال متل،التخريب،الإكراه،التهديد، العنف الجسدي، القتل الجنائي ب-الإرهاب الجماعي المنظم: -وهو الإرهاب الذي تمارسه جماعات منظمة تمولها وتشرف عليها مؤسسات أو هيئات أو دول معلنة أو غير معلنة، سعياً لتحقيق أهداف سياسية أو دينية أو مذهبية، مثال ذلك الأعمال الإرهابية التي قامت وثقوم بها جماعات ما يسمى “لالإخوان

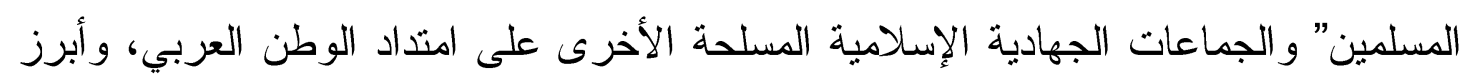
أثكال الإرهاب الذي تمارسه هذه الجماعات هي، الإرهاب الفكري ، الضغط النفسي، العنف

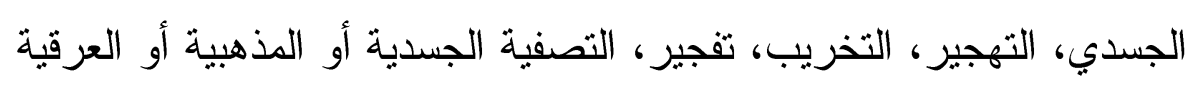

ع-الإرهاب الدوليوهو الإزهاب الذي تمارسه دولة واحدة أو أكثر عن طريق تنخير إمكانياتها الدبلوماسية أو العسكرية لتحقيق هدف سياسي، أو الاستيلاء على مكتسبات أو ثروات غير هال الإنها من الدول

وهناك من قسم الإرهاب لنوعين: إرهاب تقليدي وإرهاب جديد أو حديث. ومن أهم أنواع الإرهاب الجديد هو الإرهاب المعلوماتي ويتمثل في استخدام الموارد المعلوماتية، والمتمنلة في شبكات المعلومات وأجهزة الكمبيوتز وشبكة الإنترنت، من أجل أغراض التخويف أو الارغام لأغراض سياسية. ويرتبط هذا الإرهاب إلى حد كبير بالمستوى المتقدم للغاية الذي باتت تكنولوجيا المعلومات تلعبه في كافة مجالات الحياة في العالم، ويمكن ان يتسبب الإرهاب

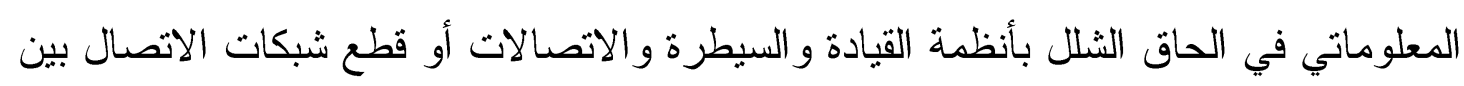
الوحدات والقبادات المركزية وتعطيل أنظمة الدفاع الجوي أو إخراج الصواريخ عن مسار ها 
أو اختراق النظام المصرفي أو ارباك حركة الطبران المدني أو شل محطات الطاقة الكبرى. 1.(1) (ويكيبيديا (1)

ويعرَّن الإزهاب أيضا بأنه (تصرف أو سلوك بشري ينزع إلى استخدام قدر من القوة القسرية، بما في ذلك الإكراه والأذى الجسدي والاستخدام غير المشروع للسلاح ولتثنيات التعذيب التقليدية والحديثة المخالفة لحقوف الإنسان الأساسية التي أقرتها الثرائع السماوية و المواثيق الدولية في التعامل مع إدارة العلاقات الإنسانية، بما في ذلك الاختلافات في المجالات الثقافية و الاجتماعية و الاقتصادية و السياسية؛ بهدف تحقيق غايات في تلك الدجالات، تتزاوح بين الإخضاع والضغط والتعديل والتهميش (الإقصاء) وقد بطول آخرين غير مستهدفين، هذا السلوك البشري القسري غير السلمي، يحدث بين الأفراد أو الجماعات أو السلطات بعضها تجاه بعض، داخل مجتمع معين، أو بين مجتمعات معينة وعناصر معينة..

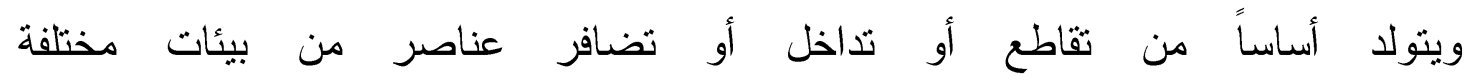

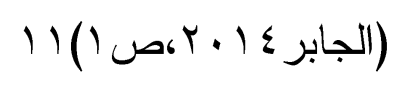

و هناك من اعتبر الارهاب فعل يشكل تهديدا رئيسيا للأمن والسلام الدوليين ،ويقوض القيم

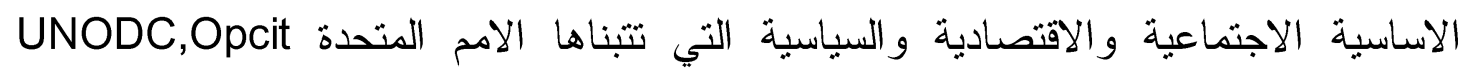

و الإرهاب في التشريع المصري: لم يعالج بوصفة جريمة مستقلة ولم يضع لها قو اعد

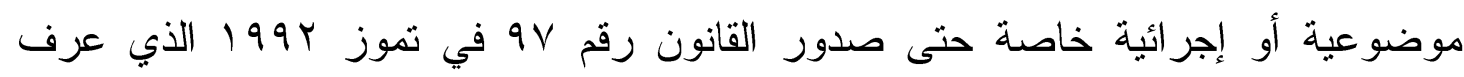
الإرهاب في مادته الثانية بقوله ((يقصد بالإرهاب في تطبيق أحكام هذا القانون استخدام القوة

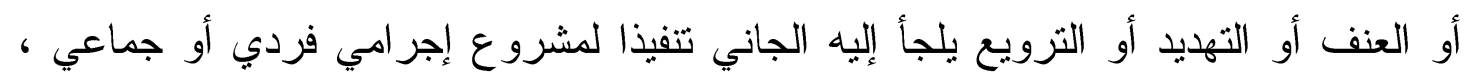
بهدف الإخلال بالنظام العام أو تعريض سلامة المجتمع وأمنه للخطر إذا كان من شأن ذلك إيذاء الأشخاص أو اللقاء الرعب بينهم أو تعريض حياتهم أو أمنهم للخطر أو إلحاق الضرر

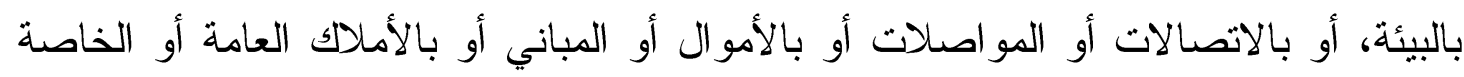

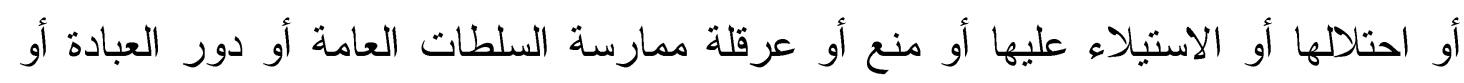

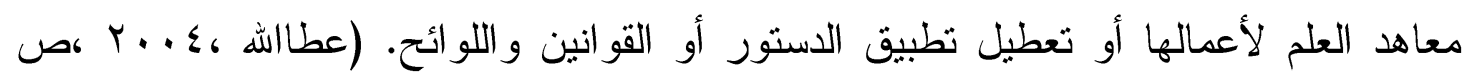


وصياغ القانون الدولي تعريف للإزهاب يقع ضمن نطاق الجرائمهو يعده جريمة دولية،فالجريمة التي ترتكب بحق الانسانية في القانون الدولي هـي الجرائم التي تتمثل في لتهن

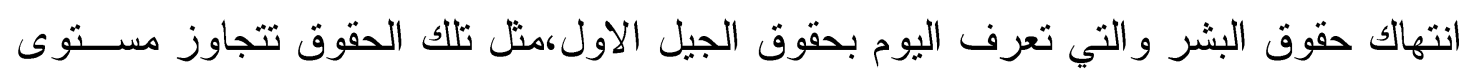
كونها مجرد حقوق اســــاسية يتمتع بها البثـر نتيجة الاتصال الاجتماعـي بين الدولة

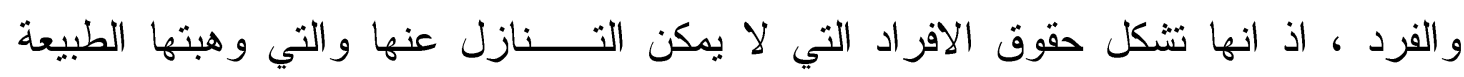

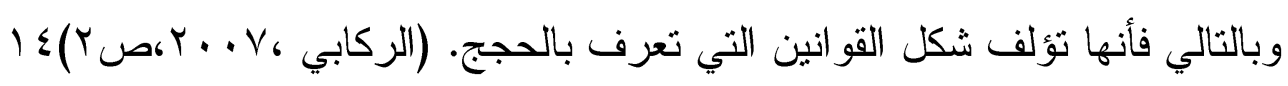

ويعرف الاهاب بأنه "أي شخص يُقدم على أي عمل عدواني يندرج في إطار مفهوم هذه الاتفاقية، إذا كان ذلك الشخص، قد تسبب بصورة غير قانونية وعن سابق إصرار في: موت أو جرح أي شخص، أو في إلحاق أضرار فادحة بالممنكات العامة والخاصة، أو إلحاق

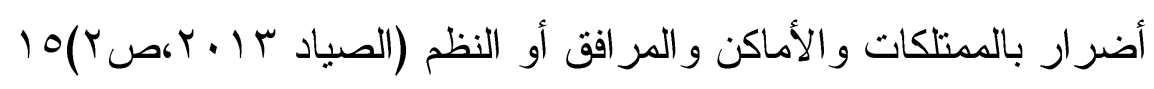

وقد عرفت لجنة القانون الدولي في المادة (9 () من المشروع المقدم من قبلها الى الدورة الأربعين للجمعية العامة للأمم المتحدة الإرهاب ((هو كل نشاط إجر امي موجهُ الى دولة معينة ويستهدف إنشاء حالة من الرعب في عقول الدولة أو أي سلطة من سلطاتها وجماعة معينة

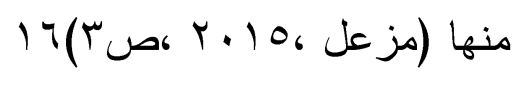

ويتضح أن الارهاب في المجتمع الدولي ليس له تعريف جامع مانع متفق عليه وذللك لوجود

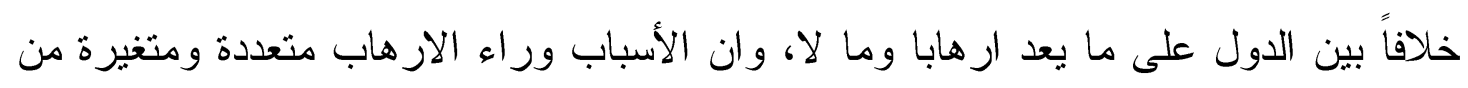
مكان لآخر ،وإن للإزهاب جوانب وأثكال متعددة من الصعب جمعها تحت تعريف واحد.

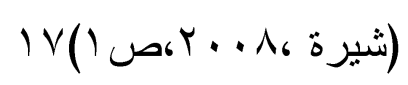

ومن ثم يكمن التعريف الإجرائي للإزهاب بأنه كل فعل يستخدم فيه القوة غير الثرعية أو

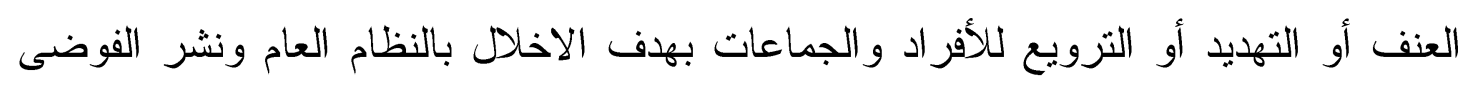
بالمجتمع ،وتهديد السلم الاجتماعي .

\section{• الصحف الاكترونية:-Electronic newspapers}

لا شك أن الصحافة الإكترونية أحدثت نطوراً كبيرًا في عالم الإعلام من خلال نشر ومتابعة الأخبار على مدار الساعة، فاستخدمت كل إمكانات الرسالة الإعلامية، وخلقت علاقة حميمية 
بينها وبين و القارئ الذي يستطيع المشاركة بكتابة الخبر و إيداء الرأي، كما استطاعت استقطاب العديد من الشرائح خاصة أنها سريعة التأثير و الوصول إلى القارئ، وتعددت الآراء حول تعريف الصحافة الإلكترونية ، ومن أهمها :-

عرفها البعض بانها تلك الصحافة التي تستعين بالحاسب في عمليات الإنتاج والنشر الاككترونية" بالرغم من أن هذا التعريف جاء قبل أن تظهر الصحافة الاكترونية، إلا أنه ينتبأ بظهور نوع جديد من الصحافة تقوم على الكمبيوتز في شتى عملياتها، من الإعداد إلى الإنتاج إلى التحرير، التوضيب حتى الوصول إلى إخراجها من خلال الأوعية الالكترونية. (علم الدين

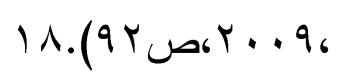

وعرفها اخر بانها تلك التي يتم إصدارها ونشرها عبر شبكة الانترنت العالمية أو غيرها من شبكات المعلومات، سواء كانت نسخة وإصدارة الكترونية لصحيفة مطبوعة ورقية، أو

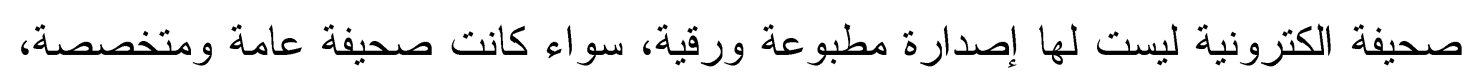
سواء كانت تسجيلا دقيقا للنسخة الورقية أو كانت ملخصات للمنشور بها طالما أنها تصدر

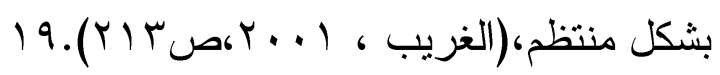

وعرفت بانها الصحافة المنشورة عبر وسائل وقنوات النشر الالكتروني بشكل دوري وتجمع بين مفهومي الصحافة ونظام الملفات المتتابعة، وتحتوي على الأحداث الجارية، ويتم الاطلاع

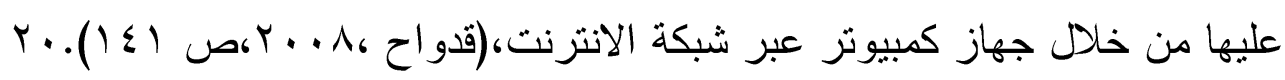
واشارت اليها اخر بانها عباره عن تكامل تكنولوجي بين اجزة الحاسبات الإلكترونية وما تملكه من امكانات هائلة،فى تخزين وتتسيق وتبويب وتصنيف المعلومات واسترجاعها فى ثوان معدودة وبين التطور الهائل فى وسائل الاتصال الجماهيرية التى جعلت العالم قريه

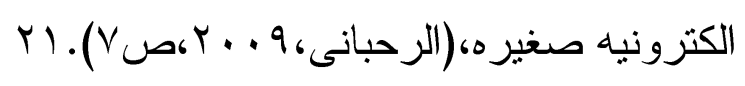

كما عرفت بانها منشور الكتروني دوري يحتوي علـى الأحداث الجارية سواء المرتبطة بموضوعات عامسـة أو بموضــوعات ذات طبيعــة خاصة، ويتم قر اعتها من خلال جهاز

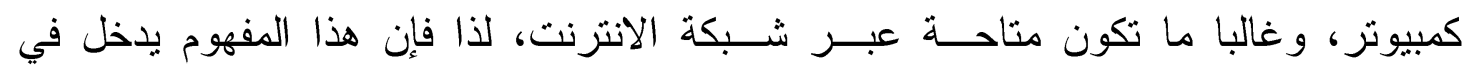

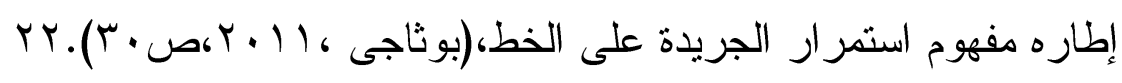


ور آها اخر بانها نوع من الاتصال بين البشر ينم عبر الفضاء الإلكتروني الانترنت وشبكات

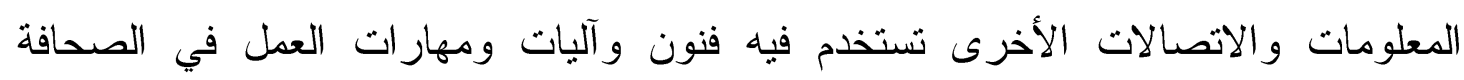
المطبوعة،مضافا إليها مهارات و آليات تقنيات المعلومات التي تتاسب استخدام الفضاء الإكتروني كوسيط أو وسيلة اتصال بما في ذلك استخدام النص والصوت والصورة و المستويات المختلفة من التفاعل مع المتلقي، لاستقصاء الأنباء الآنية وغير الآنبة ومعالجتها

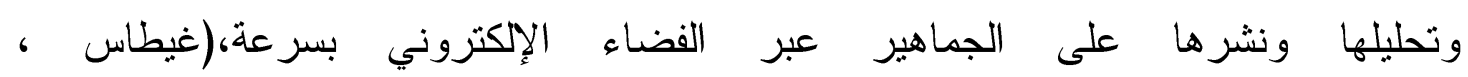

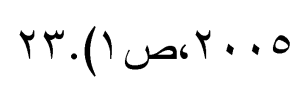

وعرفها احد الباحثين أيضابانها وسيلة من الوسائل متعددة الوسائط multimedia تتشر فيها

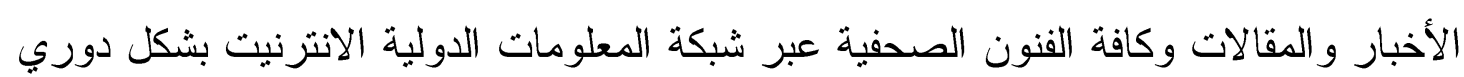
وبرقم مسلسل، باستخدام تقنيات عرض النصوص و الرسوم والصور المتحركة وبعض الميزات التفاعلية، وتصل إلى القارئ من خلا شاشة الحاسب الآلي، سواء كان لها أصل

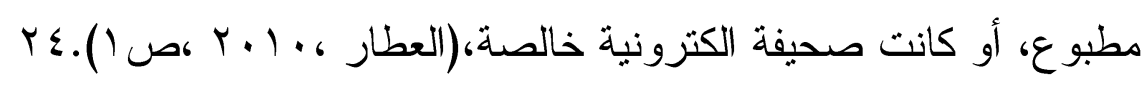

وعرفها أخر بانها الصحيفة اللاورقية التي يتم نشرها على شبكة الانترنيت ويقوم القارئ

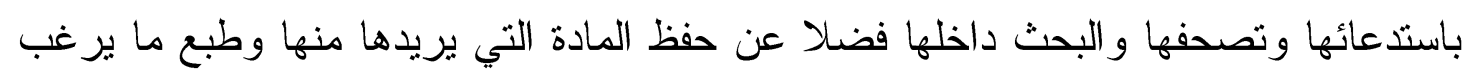
في طباعته. فهي منشور الكتروني دوري يحتوي على الاحداث الجارية سواء المرتبطة بموضوعات عامة او خاصة ويتم قر اعتها من جهاز حاسوب و غالبا ما تكون متاحة عبر شبكة الانتزنيت، والصحيفة الاككترونية احيانا تكون مرتبطة بصحيفة مطبوعة، (الجاسم

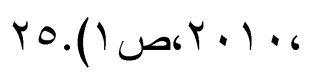

ور آها أحد الباحثين أنها نوع من الصحف يستخدم في العديد من المجالات على شبكة الانترنت مثل تنشيط التجارة الالكترونية على الصفحات الاكترونية لهذه 1999.p126 (Choobineh .). الصحف

وعرفت بانها عبارة عن نوع جديد من الإعلام يشترك مع الإعلام التقليدي في المفهوم، و المبادئ العامة و الأهداف، وما يميزه عن الإعلام التقلبدي انه يعتمد على وسيلة جديدة وسائل الئل الإعلام الحديثة وهي الدمج بين كل وسائل الاتصال التقليدي، بهدف إيصال المضامين 
المطلوبة بأنثكال متمايزة، ومؤثرة بطريقة اكبر ، وهو يعتمد بشكل رئيسي على الإنترنت التي تتيح للإعلاميين فرص كبيرة لتقليم موادهم الإعلامية المختلفة، بطريقة إلكترونية

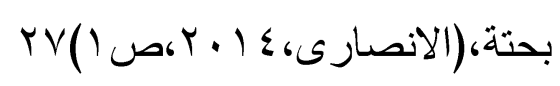

ونظر اليها البعض بأنها نوع من الصحف يتميز بخصائص عدة منها :-

- امكانية البحث عن المعلومات:- يمثل وجود وسيلة للبحث عن المعلومات في الموقع الاخباري اهمية قصوى للحصول على الاخبار و المعلومات المختلفة بسرعة وتجنب

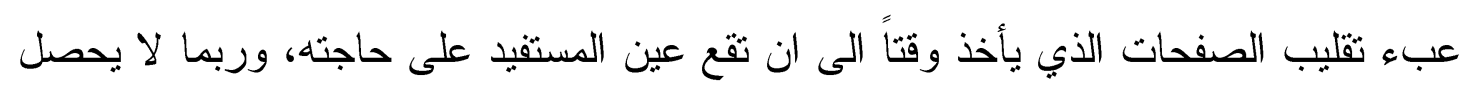
عليها بهذه الطريقة وان الصحف التي تستخدم طريقة الصورة في عرض مادتها الصحفية لا لاني

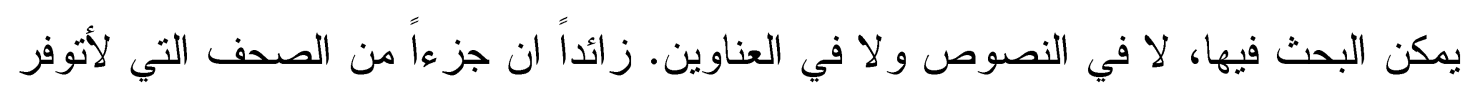
آلة بحث نستخدم نظام الوثائق المحمولة فآلة البحث البسيطة في النصوص نوجد في في في ابسط

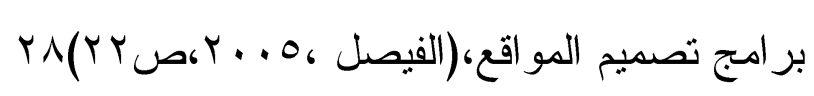

- التتوع :- - عندما جاء الإنترنت الذي سمح بإنشاء صحف متعددة العو امل ذات حجم غير

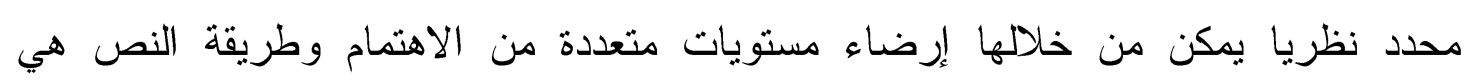
المحرك لهذا التتويع من الإعلام الإكتروني ، الذي يمكن من تكوين نسيج إعلامي حقيقي

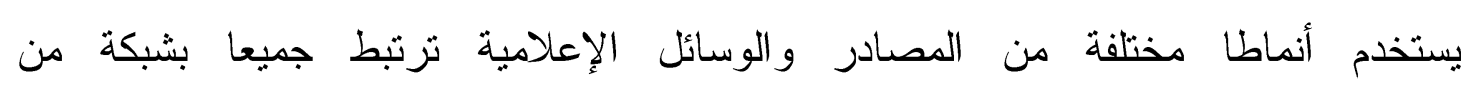

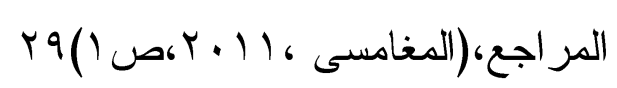

- خاصية المرونة:- تبرز خاصية المرونة بشكل جيّّ بالنسبة لمستخدمي صحافة الإنترنت،

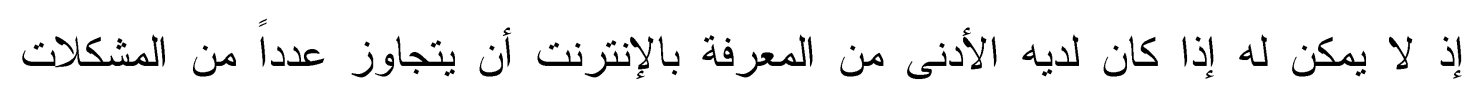
الاجر ائية التي تعترضه.

- سهولة العرض:- حيث تعد سهولة العرض أحد أهم عوامل تفضيل الوسائل لدى

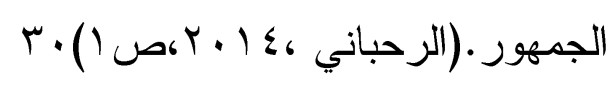

ورآها البعض الاخر بأنهانوع من الصحف المعاصرة نواجه جملة من التحديات الذاتية و الموضو عية يمكن إيجاز ها كالتالي:- 
- - الذاتية: - تتقسم التحديات الذاتية التي تواجه الصحافة الالكترونية إلى قسمين .. الأول مادي و الثاني مهني ..التحدي المادي يتمثل في ضعف الموارد المادية للمواقع الإخبارية الصحفية والتي ترغب في المنافسة ولا تجد المال الكافي من أجل القدرة التشغيلية ، أما التحدي المهني فيمكن تلخيصه في التالي:ضعف القدرات المهنية لدى عظم المشتخلين في

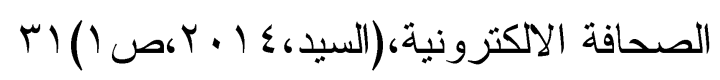

-ايضا عدم وجود الثقة لاى المسؤولين بالصحف الالكترونية وهذا قد يقلل من وجود السبق الصحفي لدى هذه الصحف،وان غالبية الصحف الالكترونية في الوقت الحالي يعيب عليها اعتمادها الكامل على مو اقع الصحف المطبوعة على شبكة الانترنت كمصدر للأخبار مع عدم

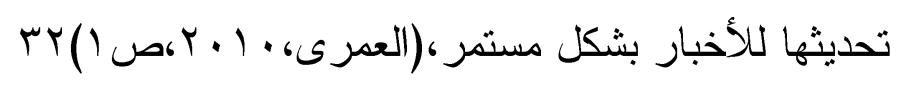

- قلة الشرعية القانونية الني تعاني منها الصحافة الاكترونية، مثلها مثل معظم الخدمات الاككترونية كالنقود الاككترونية و التوقيع الاككتروني، و من المنتظر أن يتوصل الساسة التكنولوجيين و القانونيون إلى إيجاد حلول لها، وغياب التخطيط و عدم وضوح الرؤية المتعلقة

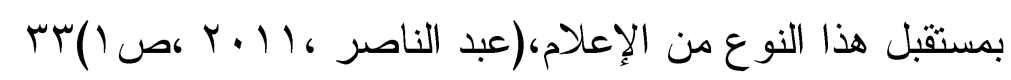
ونظر اللأهمية المتز ايدة للصحافة الإكترونية نم انشاء الاتحاد العربي للصحافة الإلكترونية،

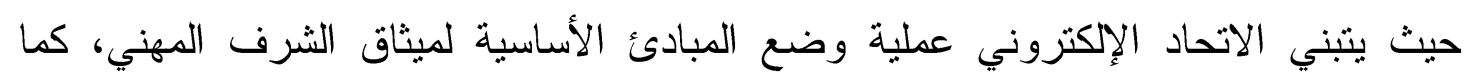
تشمل مبادئ مسودة الميثاق التي أعدها الاتحاد العربي للصحافة الإككترونية عدة بنود منها: احترام حقوق الإنسان في الحصول علي الحقائق هو الواجب الأول للصحفي، الدفاع عن مبادئ الحرية في الحصول علي المعلومات ونشرها، ضمان الحق في النقا و إبداء الرأي و التعليق عليه، اتباع وسائل نزيهة في الحصول علي المعلومات والصور و الوثائق، احترام القيم الاجتماعية والثقافية والدينية للمجتمع، الامتتاع عن التمييز بين المواطنين بسبب العنصر

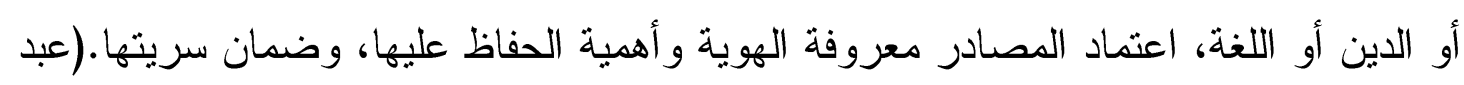

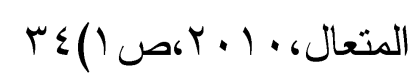

ومن ثم يكمن التعريف الإجرائي للصحافة الالكترونية في أنها الصحف الصادرة على شبكة الانترنت، وقد يكون لها أصل ورقى،أوتتشر على الانترنت فقط، وتصدر دوريا، وتجدد 
أخبارها على مدار الساعة،وهى بوابة القاهرة الالكترونية ،جريدة الوطن المصرية الآكترونية ، صحيفة اليوم السابع الالكترونية كبوابة الفجر الالكترونية ، بوابة البديل الاخبارية .

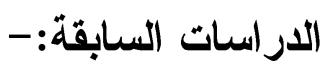

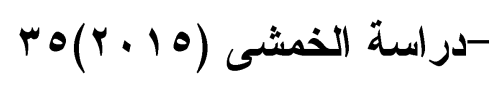

بعنوان (دور التربية الاسرية فى حماية الابناء من الارهاب)

تدور الدراسة حول هور الإرهاب في الآونة الأخيرة بالمملكة العربية السعودية ليكون مشكلة اجتماعية لها مسبباتها الاقتصادية و الاجتماعية والسياسية بصورة لم يسبق لها مثيل في المملكة، ومما زاد من خطورة هذه المشكلة نظرة بعض القائمين بتلك الأعمال الإرهابية على أن أفعالهم بطولية، بالإضافة إلى الآثار السلبية التي تتركها على المجتمع بكل قطاعاته، وتعنى التربية الأسرية برفع درجة وعي الفرد في مختلف الأعمار وفي شتى الظروف و الملابسات وتتمية السلوك الإنساني وتغييره وتطويره حتى تتكون لديه المو اطنة الصالحة في مجتمعه و المنهج العلمي كان المحدد للار اسة ،ومعتمدة على المنهج الوصفي التحليلي ،وتمنت أداة الدراسة فى الاستبيان لجمع بيانات ،ومن أهم نتائج الدراسة:- ان الاسرة السوية صاحبة الدور الهام فى حماية الابناء من براثن الارهاب بكل أثكاله - ان الاسرة المتصدعة المريضة أبنائها الاكثر عرضة للانحراف والارهاب فى المجتمع السعودي - كثفت الدراسة ان السبب الرئيس فى تصدع بنيان الأسرة وانحراف اعضائها يرجع للمقام الاول لقلة الوازع الديني وضعف التمسك بالتعاليم و القيم الإسلامية الصحيحة .

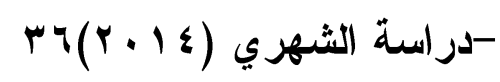
بعنوان "التطرف والارهاب الإكتروني " حيث حاول الباحث رصد بعض خواص ثقافة النطرف و العنف على المشهـ الإكتروني ، حيث تعتمد هذه المو اقع على التطرف والغلو ولا تتيح الفرصة للحوار مع الراب المخالف بل 
تقمعه وتخونه وتكفره احيانا ، اضافه الى الاستعداء و التأليب على المخالف وتشويه سيرته وتتبع اسراره ونشرها ، تعد من الدراسات الوصفية، واستخدت الدراسة المنهج الوصفي التحليلي و الاستبيان لجمع البيانات . توصلت لعدة نتائج من اهمها :-

- يرجع نجاح المجرمين فى استغلال الانترنت فى انشطتهم الى ضعف التشريعات و العقوبات المخصصة للأنماط الجديدة لهذه الجرائم - كثفت الدراسة عن ضعف الامكانيات الأمنية فى الرصد و التحقيق من هذه المواقع ومر اقبتها بطريقه فعاله .

كثفت الدراسة عن عدم كفاءة الردود المنطقية الصحيحة على شبه المتطرفين و المواجهة

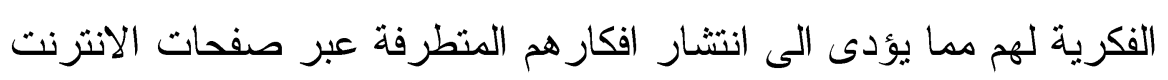

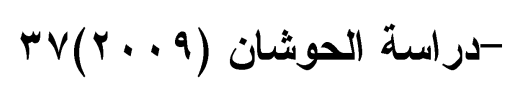

بعنوان :- وظيفة الاسرة و المدرسة فى تحصين أبنائها ضد التطرف والارهاب وتعزيز الانتماء الوطني

تتاول البحث دور الأسرة كأهم العوامل الاجتماعية والتي تمثل النواة الأولى في علاقة الفرد

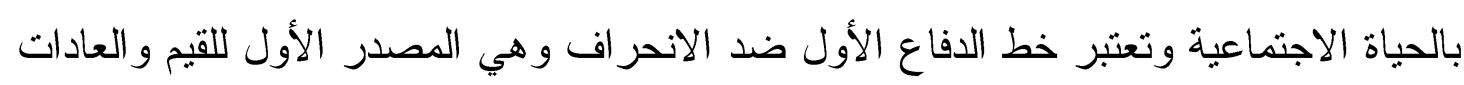
و السلوكيات التي يتعلمها الفرد ومنها تتكون شخصيته الاجتماعية من حيث الوعي و السلوك. كما أن المدرسة من أهم المؤسسات الاجتماعية التي لجأت إليها المجتمعات الحديثة لتلبية

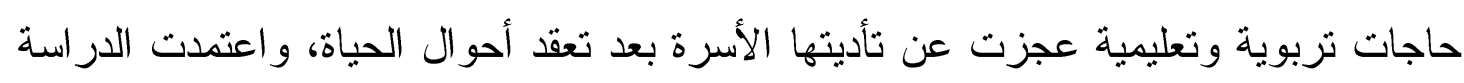

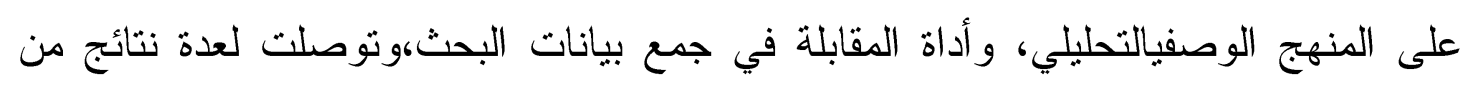
أهمها :

- - أوضحت الدراسة ان الاسرة المتصدعة من أهم العوامل الاجتماعية التي تدفع الافر اد الى التطرف و الارهاب 
- بينت ان المدرسة ومناهجها التربوية والتعليمية دورها في تعزيز الانتماء الوطني عند

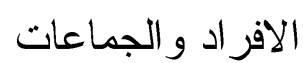

- كثفت أن مشكلة التطرف الفكري والار هاب ترجع الى انعدام الانتماء فى المجتمع

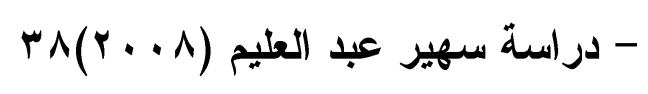

بعنوان "الارهاب و الانترنت دراسة حاله فى ضوء التجربة|لمصرية "

تدور حول الصلة الوثيقة بين الارهاب والانترنت ، ومن خلال هذا توضح دور الانترنت فى

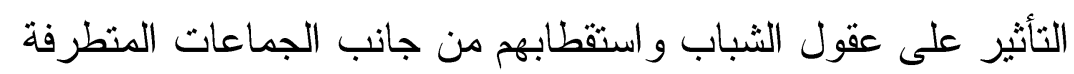
اعتمدت على منهج دراسة الحالة، ومنهج تحليل المضمون لبعض مواقع الانترنت، و اسلوب العينة للار اسة الميدانية على شباب من القاهرة الكبرى -توصلت لاهم النتائج من اهمها: - حرص غالبية افراد العينة على استخدام الانترنت باعتباره الوسيلة الاسرع لتقديم المعلومات حول القضايا الملحةو العاجلة

- كثفت عن عدم ثقة اغلب افر اد العينة فى بعض الاحيان فى هوية المو اقع الإلكترونية التي تقدم معلومات فى مجالات معينه كالطبي و الديني. - كثفت الدراسة عن ان غالبيه افراد العينةر أوا ان الصحف الإلكترونية قامت بتغطية جيده لبعض الاحداث الإرهابية/لتى مر بها المجتمع المصري.

$$
\text { - در اسة محمد الالوفى (r... }
$$

بعنوان " العو امل الفاعلةفي انتشار جرائم الارهاب عبر الاترنت "

ترى الدراسة ظهور مجموعه مستحدثه من جرائم الارهاب عبر شبكة الانترنت التي باتت تهدد الاستقرار الأمني للمجتمعات، وقد انتشرت هذه الجرائم بسرعه مذهله لم تسنطع معه التشريعات الوضعية الحالية مو اجهتها او تحريمها 
اعتمدت الدراسة على المنهج الوصفي التحليلي، ومنهج تحليل المضمون لبعض المواقع الإلكترونية، وتوصلت لعدة نتائج من اهمها: -

- - ان أكثر العوامل الفاعلة في انتشار الارهاب عبر الانترنت يرجع الى عدم الرقابة الأمنية الجادة على هذه المو اقع الإلكترونية.

- اوضحت الدراسة ان كثير من جرائم الانترنت لا يتم الابلاغ عنها لعدم اكتثاف الضحيةلها، و واما خشيه من التشهير ، او الذكاء الكبير لمرتكبيها. • كثفت عن وجود جرائم مستحدثه عبر شبكة الانترنت دعمت ونشرت الارهاب الإككتروني بأشكالها لمختلفة.

\section{- در اسة يوسف حامد(1990) - ع (190)}

بعنوان "المتغيرات السياسية والاقتصادية والاجتماعية المرتبطة بمشكلة|الإهاب"

تدور حول أهم الأسباب التي ساعدت على تكوين الجماعات الإرهابية ومنها، اقتصادية، اجتماعية أسرية، ونفسية، ومشكلة وقت الفراغ وجماعة الرفاق، وتوضيح بعض مظاهر

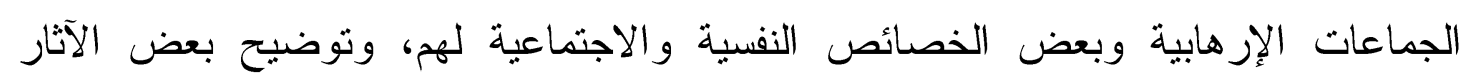
المترتبة على الانضمام إلى الجماعات المنطرفة، واستخدمت النهج الوصفي التحليلي، وأداة الهابه لملاحظة و الاستبيان لجمع البيانات، ومن أهم نتائج الدر اسة: -

- اوضحت ان العوامل الاجتماعية والنفسية كان لها الدور الكبير في وجود الجماعات الارهابية

- كثفت عن الانعز الية والاغتراب و الاقصاء الاجتماعي و العنف،كأهم الاثار المترتبة على الانضمام للجماعات الارهابية.

ا التعليق على الاراسات السابقة: -

يتضح من خلال هذا العرض من الدراسات السابقة، التي تتاولت العو امل الاجتماعية للإزهاب، بأنها تتسم بالندرة في هذا الجانب من ظاهرة الارهاب، حيث ارتبط ما لتان 
كتب عن ذلك بالمقالات والتحقيقات، وليست أبحاث علمية متخصصة، كما أن ما يميز هذا البحث أنه يتتاول العوامل الاجنماعية لظاهرة الارهاب في الصحافة الالكترونية، وخاصة في المجتمع المصري، حيث لم تتعرض أي دراسة لمثل هذه القضية، بل أن الغالبية العظمى من الدراسات تدور حول الارهاب الإكتروني فقط.

الاجر اعات المنهجيةللار اسة:- - أ

المنهج:اعتمدت الدراسةعلى منهج تحليل المضمون الكيفي للصحف الالكترونية التي تتاولت

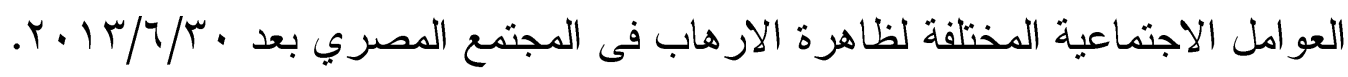

الاداة: -تم استخدام الملاحظة العلمية لبعض مواقع الصحف الالكترونية موضوع البحث ،للاستفادة منها في تحليل مضمون هذه الصحف حسب توجهات البحث العلمية ،و دليل تحليل المضمون الكيفي ويتمثل في العوامل الاجتماعية التي تؤثر على انتشار الارهاب في تهي المجتمع المصريفى الصحف الالكترونبة مثل ، العوامل الاسرية (التفكك الاسرى ، العنف

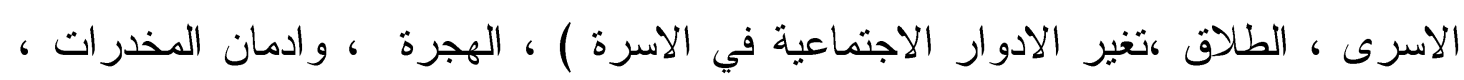

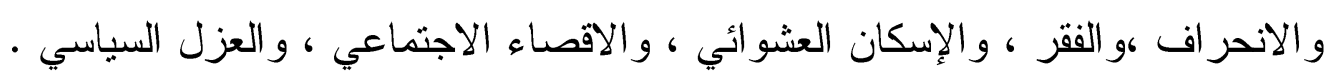

\section{مجالات الدراسة:}

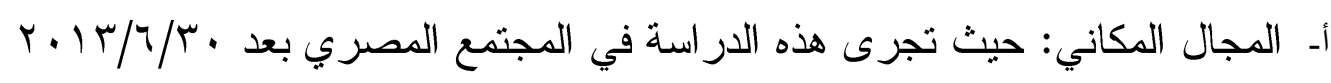

بـ المجال الزماني: حيث تقوم هذه الدراسة بتحليل مضمون كيفي للصحف الإلكترونية في

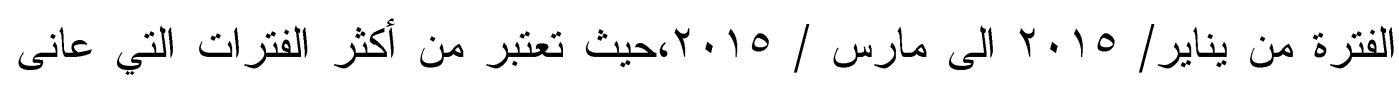
منها المجتمع المصري من الارهاب بكل أشكاله .

ج ـالمجال البشرى: حيث اعتمدت الدراسة على عينه من الصحف الإلكترونية المصرية ، تتمتل فى خمس صحف الكترونيه ، لها انتشار واسع على شبكة الانترنت وهى ( بو ابة إنه الفجر الإككترونية - جريدة الوطن المصرية الإلكترونية- بوابة البديل الإكترونية - اليوم السابع الإلكترونية - بو ابة القاهرة ) 
• تحليل مضمون للصحف الاكترونية التي تناولت العو امل الاجتماعية لظاهرة

الارهاب بالمجتمع المصري

- يتم تحليل المحتوى المنشور على الصفحات الالكترونية لهذه الصحف، متضمنا التحليل السوسيولوجي للباحث لهذه العوامل الاجتماعية لظاهرة الارهاب في المجتمع المصري، مستخدما الملاحظة العلمية ودور ها في خدمة الاهداف العلمية للدر اسة.

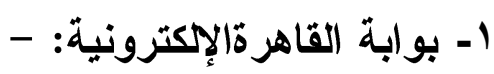

جريدة الكترونيه تهتم بالشأن المصري، وتركز على هموم المواطن، وتجدد اخبارها

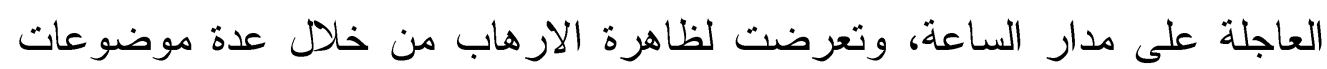

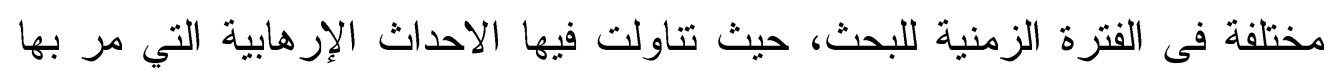
المجتمع المصري، الا انها لم تتعرض للإبعاد الاجتماعية لنلك الظاهرة الا فى خمسة موضوعات اما عن طريق الاخبار المصورة، او عن طريق المقالات وقد انحصرت هذه العو امل الاجتماعية لظاهرة الارهاب على صفحات هذه الصحيفة الإكترونية فى لهي الاتي:-

أ) الاقصاء الاجتماعي : ورات الصحيفة ان الاقصاء الاجتماعي ينتج اساسا عن الاقصاء او العزل السباسي للعديد من اعضاء الجماعات السياسية فى المجتمع المصري ،ويتضح من ذلك ان العزل السياسي لهؤلاء الافراد مع التغطية الإعلامية المؤدية ، جعلهم فى حالة اقصاء اجتماعي فى المجتمع ، وخاصه هن المجتمع المحلى الذى ينتمون اليه مما جعلهم فريسه سهله للتغرير بهم نظرا لسخطهم على المجتمع و افر اده ، لأنه السبب فى لفظهم من الاقارب و الاصدقاء . ب) الهجرة غير الثرعية : حيث تتاولت ذلكفى بعض التحقيقات المصورة للشباب

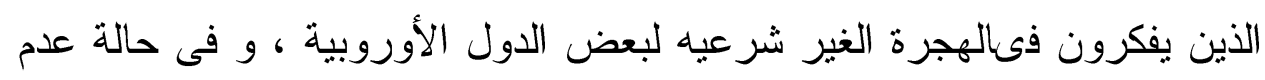
نجاحهم فى هذه المحاو لات قد يؤدى لانحر افهر ، و انضمامهم للجماعات الإرهابية خاصه فى ظل تدنى فرص العمل ، وغلاء المعيشةفى المجتمع المصري ،كما

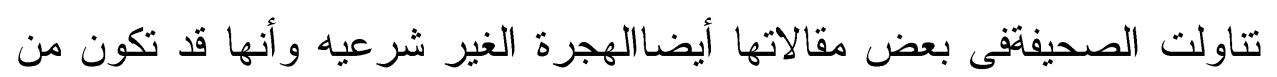


أسباباصطياد الثباب، و اغر اءهم بالمال، ونسهيل انضمامهم للجماعات الإرهابية تحت مسميات عديده منها الجهاد ومحاربة الكفار.

ج- انتشار المخدرات : حيث تتاولت الصحيفةالإكترونية مشكلة المخدرات والادمان فى تحقيقين مصورين حول حملات مواجهة هذا الوباء اللعين ، وكيف انه بعد من الاسباب الاجتماعيةالرئيسةفى وجود الارهاب و التشجيع عليه فى المجتمع المصريفى تلك الفتزة ، وقد يتضح ذلك من خلال تجفيف المنابعالماديةالتي كانت تقوم على تمويل الجماعات الإرهابية، لجأت الى هذه التجارة الغير مشروعه لتغطى تكاليف العمليات الإرهابيةالتي تقوم بها داخل حدود الوطن وخاصه فى سيناء ، أو من خلال هده وقوع الثباب المصري تحت وطأة الادمان حيث أنه من العوامل الاجتماعيةالتي تجعلهم ينضمون للجماعات الإرهابية نظر اللمبالغ الماديةالطائلةالتي يحصلون عليها من هذه الجماعات وبالعملة|لصعبة ، مما يجعلهم يؤمنون المال المطلوب لتغطيه تكاليف ادمانهم للمخدرات كما قد يشعر هم بان لهم دور افى المجتمع الموجودين بين افر اده ،و أن كان دور مرفوض اجنماعيا

\section{r - (جريدة الوطن المصرية|الإكترونية:-}

- تعتبر من الصحف الإكترونيةالمصريةالتي تعرض الاحداث المصرية و القضايا

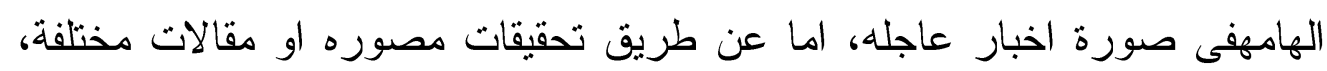

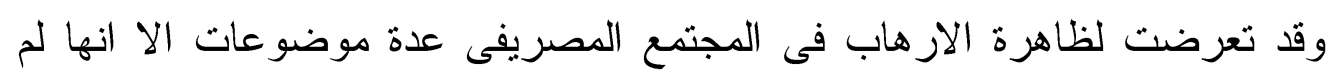

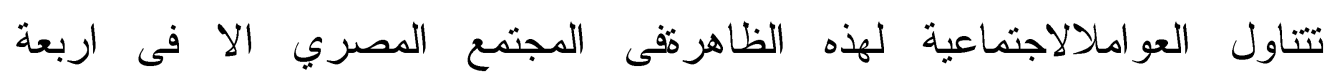
موضوعات ما بين تحقيقات مصوره ومقالات لبعض الكتاب، وتمثلت هذه لهاء

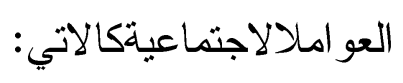

أللوظيفةالاجماعية للدين : حيث تناولت هذه القضيةالاجتماعية من خلال احدى مقالاتها ، حيث تم الحديث عن خصوصية الدين فى مصر كما فى كل مجتمع ، والتي تتبع من الطريقةالخاصةالتي يفهر بها الناس الدين ، وكيف ان غالبية الجماعات الإرهابية تستغل الدين كعامل اجتماعيفى المجتمع من اجل تجنيد اعضاءها 
تحت وازع محاربة الخارجين على الدين على حد قولهم ، لذلك دعت هذه الصحيفة الإكترونية الى ضرورة تجديد الخطاب الديني وتحقيق الفهم الصحيح للتعاليم والقيم

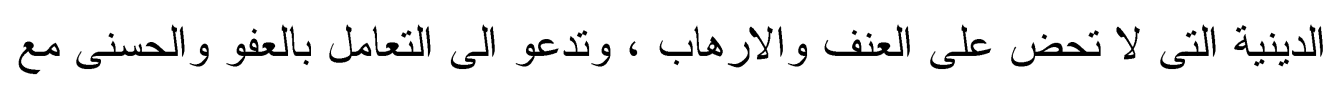
المسيئين ، واهتمت فى احدى التحقيقات المصورة و التعليق عليها بضرب الامثال من التراث الإسلاميالتي تعبر عن الفهم الصحيح للاين الإسلامي وكيفية التعامل مع المخالفين فىالر أي وعدم اللجوء لإرهاب الغير ، ومن خلال تحليل المضدون يتضح

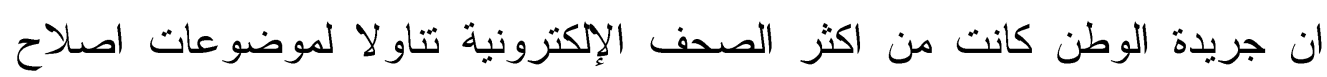

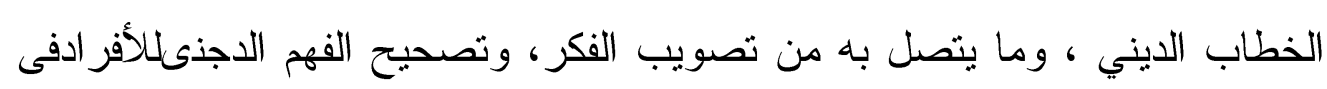

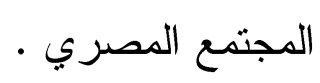

بالاقصاءالاجتماعي : حيث تناولت هذا البعد الاجتماعيلاجزهابفى مقال وفى تحقيق

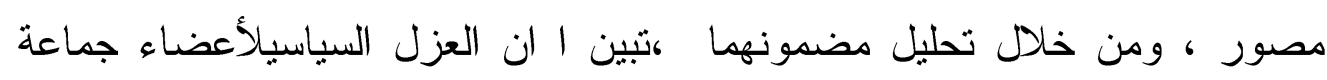
الاخوان المصريةمثلا ،وبعض الجماعات المؤيدة لها وما ترتب عليه من العزل

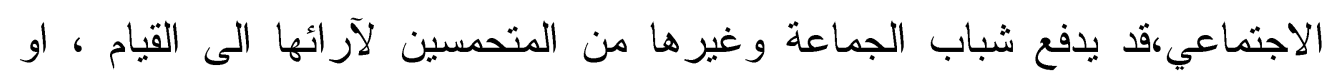
المشاركةفى الاعمال الإرهابيةالتي انتشرت فى تلك الفترة، كتفجير شبكات الكهرباء ،وصنع القنابل البدائية ووضعها بين المارةفى الثوارع المصرية.

ج- البطالة : - حيث تتاولت هذا البعد الاجتماعيفى احدى مقالاتها، ومن تحليل

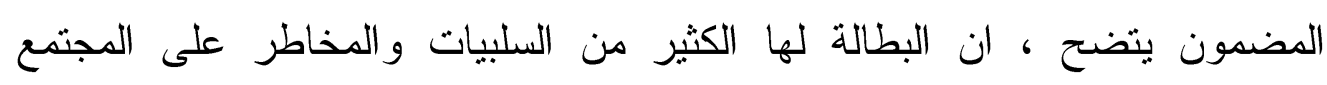

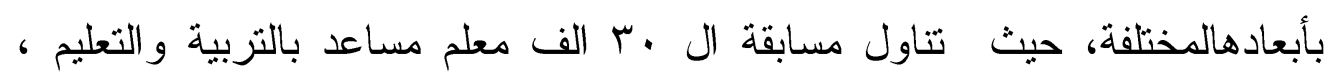

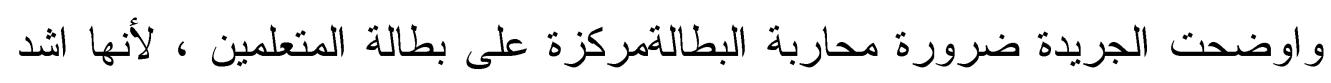
خطر على المجمع من غيرها، وقد تؤدى الى لجوء هؤلاء العاطلين الى الجماعات

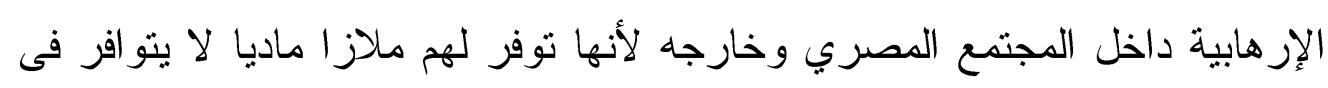
المجتمع الذى ينتمون اليه 
- تعنبر من اكثر المواقع الإلكترونية|لإخبارية|لطى يقبل عليها متصفحالانترنت،حيث

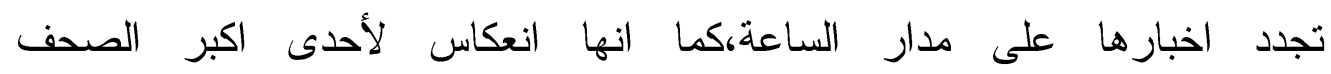
الورقية|المصرية (اليوم السابع )، ومن خلال تحليل المضمون لها وجد ان هناك بعض العواملالاجتماعية لظاهرة الارهاب التي تتاولتها هذه الصحيفة|لإكترونيةفى هذه الفترة اما فى صورة تحقيقات مصوره او مقالات لاحد الكتاب وتتمتل فيلاتي : ألعو امل الأسرية : حيث تعرضت الجريدة فى ثلاثة موضو عات للأبعاد الأسرية التي

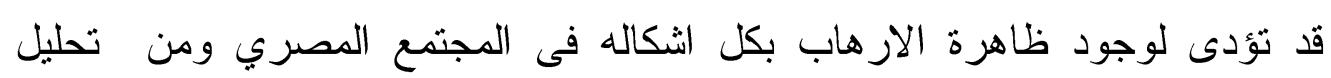
المضمون يعتبر العنف الاسرى ، و القسوقفى التعامل بين الاباء والابناء ، و التفكلك

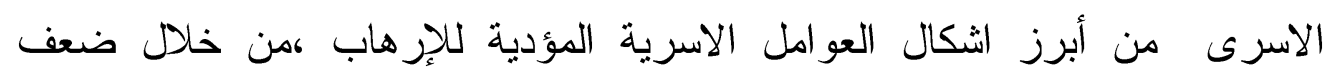

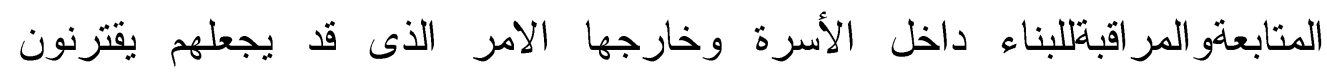
بأصحاب السوء الذين يدفعونهم الى الانحراف بكل صوره ، ويتعرضون للفكر

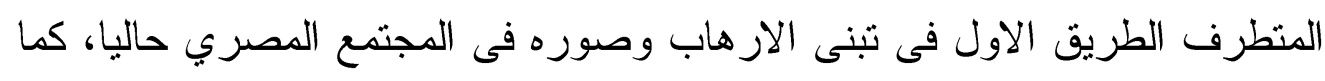
اشارت الصحيفةفى احدى تحقيقاتها المصورة حول انحراف رب الأسرة وتمثلت فى لهى حاله كانت لسيده ارمله و ومن خلالها أتضح مدى غياب القدو الحسنه فى محيط الأسرة، مما عرض احد اباءها الذكور للانضمام للجماعات الإرهابية، كما اثشارت الصحيفقفى احدى مقالاتها لدور الآسرثفى محاربة الارهاب كظاهره اجراميهفى

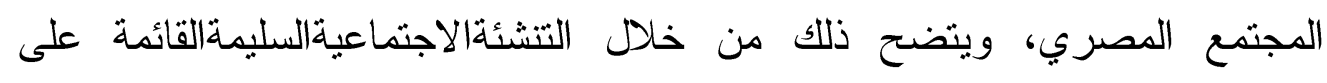
العطف و الحنان بين الاباء والابناء ، و البعد عن العنف الاسرى بكل اثكاله اللفظيو البدني ، و التوجيه التربوي السليم للثباب فى الآسرة .

بالانتماء : حيث تعرضت فى اكثر من ثلاثة موضوعات الى الانتماء كبعد اجتماعي يؤدى فقده الى تتامى ظاهرة الارهاب فى المجتمع المصري ، ومن تحليل مضمونها ، عبرت عن نقص شعور بعض الثباب بحقوقهم الاجنماعيةو السياسيةفى المجتمع المصري ، مما قد يؤدى بهم الى رفض وجودهم فى المجتمع و وبالتالي يتنبون سياسة التخريب لصالح من بدفع اكثر ، وحاولت توضيح ان الانتماء الوطني بكل 
اثكاله يعتبر من اهم الاسباب الاجتماعيةالحقيقيةالتي يؤدى نقص وجودها حتما الى

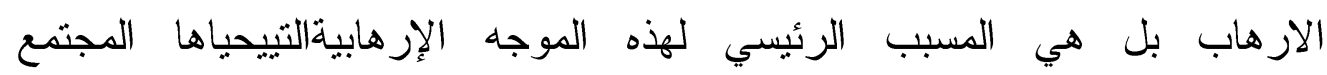

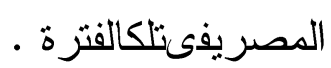

\section{ع - بوابة الفجر الإكترونية :-}

- تعتبر من الصحف الإكترونيةالتي لها صدى واسع على مواقع الانترنت ، ويلجا اليها

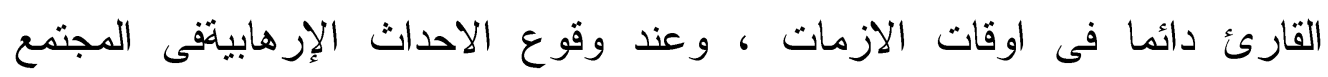

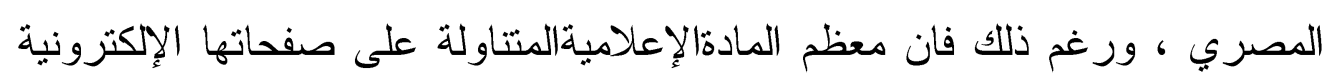
المتعلقة بالإزهاب ، تظهر فى صورة تحقيقات مصوره ، ومن خلال تحليل المضمون لمحتوى هذه الصحيفة/إلكترونية لهذه الفترة وجد ان العواملالاجتماعية لظاهرة الارهاب بالمجتمع المصري تكمن فىالاتي :-

ألأسرة : حيث ان من خلال بعض التحقيقات لهذه الصحيفة وتحليل المضمون لها، يتضح تتوع العوامل الأسريةالتي رأتها تؤدى الى الارهاب فى الدنمع الدصري

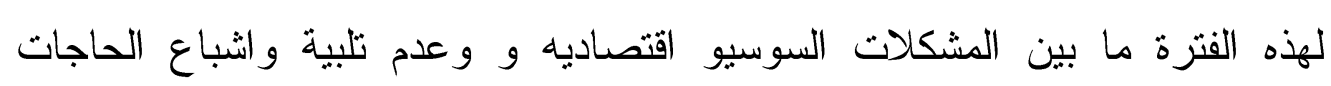

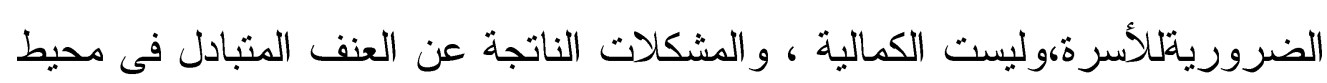
الأسرة الواحدة ، كما تتاولت هذه الصحيفةفى احدى مقالاتها هجرة رب الأسرة لخارج

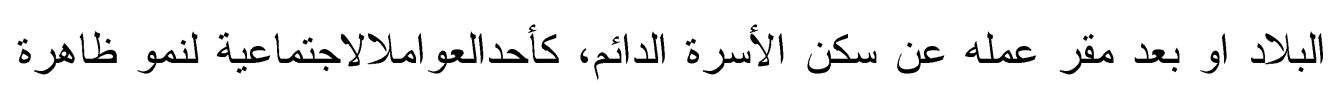

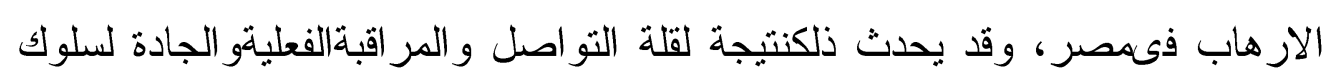
الابناءمن رب الاسرة ، خصوصا فى ظل عمل الزوجة ايضا مما يجعلهم تربه

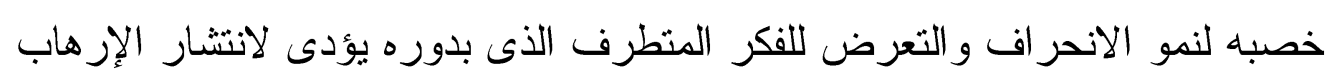

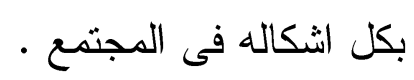

بالاقصاء الاجتماعي : ومن خلال تحليل التحقيقات المصورثيتضح أن الاقصاء

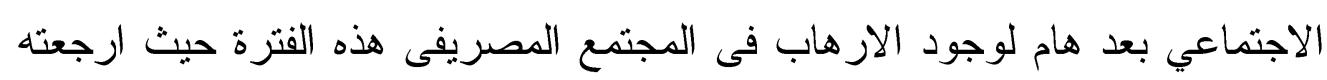

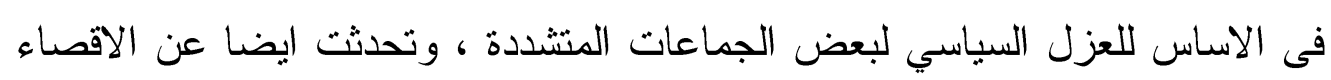
الاجتماعي داخل حدود الأسرة الذى يتسبب فى الاغتراب النفسيوالاجتماعي الناتج 
عن لفظ الأسرة لاحد اعضائها نتيجةلإدمان او الانحراف ، وعدم اتباع الطرق

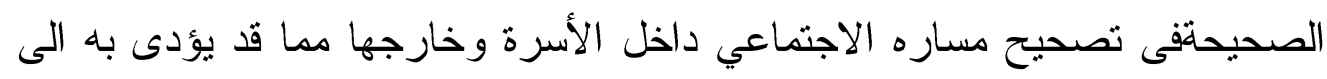
الوقوع فى أيدى الجماعات الإرهابية ، وخاصه فيلالأسرةالبدويةالنقليدية (المجتمع

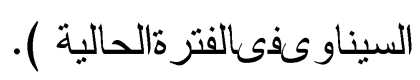

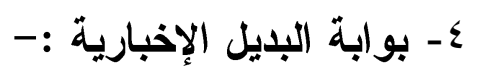

- تعتبر من الصحف الإكترونيةالتي تغطى الاحداث المصريةالساخنة على مدار الساعة خاصه الاحداث السياسيةو الجنائية ، ولذلك اصبحت لها دور هام ، وصدى لهى أعلاميالكتر وذنىتتامي على صفحات الانترنت بين القراء ، ومن خلال تحليل المضمون للمادةالإعلاميةالخاصفبالأحداثالإرهابيةفى المجتمع المصريالتي تتاولتها ، تم رصد مجموعه من العواملالاجتماعية لظاهرة الارهاب فى المجتمع المصري

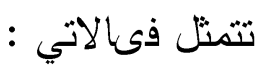
أللفقر والعشوائيات : ومن خلال تحليل مضمون بعض التحقيقات التي تناولت العشوائيات كأحد اهم مظاهر الفقر فى المجتمع المصري نم تتاول يتضح كيف ان سكان العشو ائيات يفتقدون الكثير من مقومات الحياه الاجتماعيةو الاقتصاديةو السياسية ، مما يزيد نسب الانحر اف بكل انو اعه ،و اوضحت الجريدةفى احدى تقارير ها المدعم بالصور كيف انها اصبحت مصدر أساسيفى لجوء شبابها للجماعات الإرهابية،كما

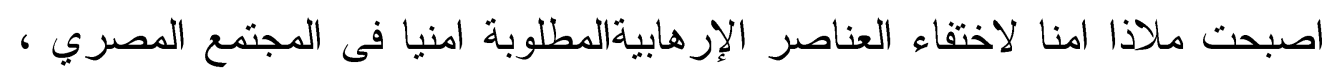
وحاولت أن توضح أيضابان القضاء على العشوائيات ليس فى اختفائها ، بل فيتطوير ها ماديا وبشريا و انثاء الأجهزةالرسمية وغير الرسميةالتي تهتم بالحياة

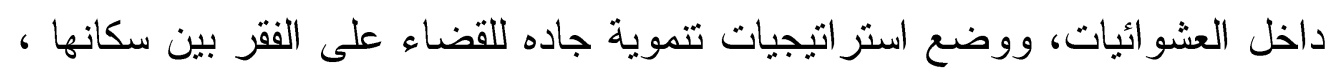
ومنع امندادها واتساع رقعتها اى العمل على تحجيمها فى مساحات محدودة ليسهل

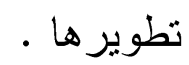

بالعزل السياسي : ومن خلال تحليل المضمون لتناول هذا البعد الاجتماعي كيتضح أنهاتتاولت العزل السياسي كمفهوم بديل للإقصاءالسياسيوالاجتماعي لبعض افراد 
المجتمع ، سواء كان هذا العزل رسمي او غير رسمي، وما قد ينتج عنه من ضعف ، و انعدام للانتماء الوطني ، وتقليص فرص الاندماج فى انظمة المجتمع من جديد

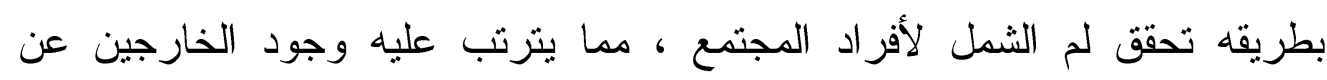
القانون ، وبالتالي ظهور الجماعات الإرهابيةالتي تتكون فى الاساس من الشباب المرفوض اجتماعيا ، و لا يحصلون على ادنى حقوقهم القانونية او المدنية. ج- الأسرة :وقد تتاولت العو امل الأسريةفى احدى مقالاتها ، ويتضح أنها عبرت عن

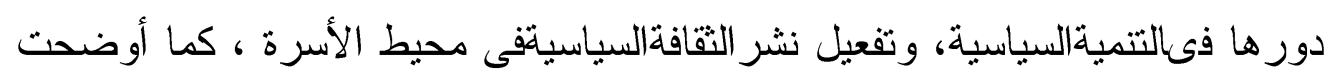
كيف ان الأسرة الغير سوية مسئوله عن امداد المجتمع بالأفراد الغير صالحين

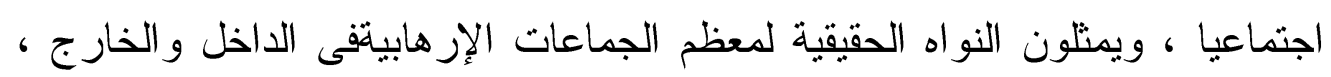

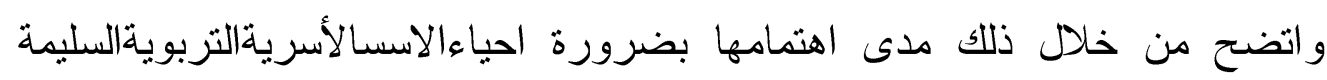

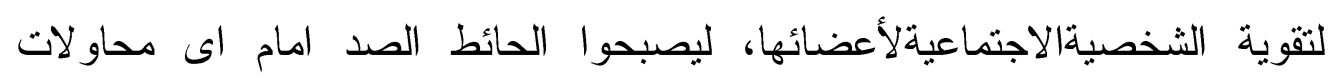
للجماعات الإرهابيةالر اغبة فى تجنيدهم. 
منخلال تحليلأهم العوامل الاجتماعية لظاهرة الارهاب فى المجتمع المصريفى الصحف الاكترونية فى فترة الدراسة توصل البحث لعدة نتائج تمثلت فى لالاتي :-

- اوضحت الدراسة ان مساحة التعرض للعواملالاجتماعية لظاهرة الارهاب فى

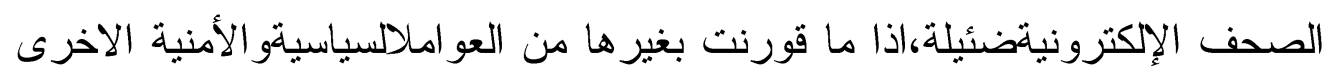
كوالتي تحتل الاسود الاعظم من المادة الاعلامية المعروضة للأخبار المتعلقة بالأحداث الارهابية فى الصحف الالكترونية المصرية .

- كثفت الدراسة ان العواملالاجتماعية لظاهرة الارهاب فى المجتمع المصري،من اقل الاسباب التي اهتم بها القائمين على الامر من رجال السياسة والامن القومي، لأنهافى القيه

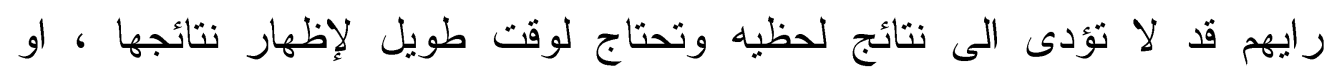

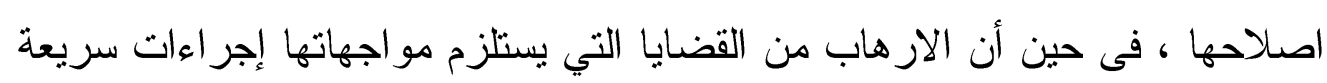
لتأمين الوطن و المو اطنين .

- كثفت الدراسة ان من اهم العواملالاجتماعيةالتي قد تؤدى الى انضمام الثباب

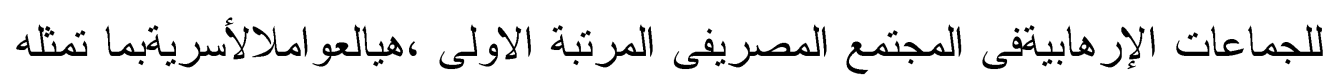

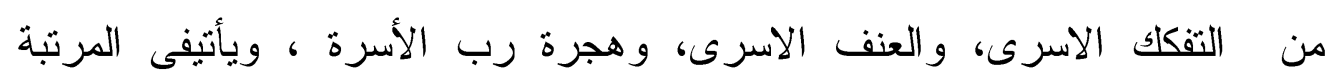
الاخرى الاقصاء الاجتماعي،كعاملهام قد يدفع بعض الافر اد والجماعات الى نفس النهج الإزرابيفى المجتمع المصريفى الفترة الحالية .

- اوضحت الدراسة ان هناك شبه اتفاق بين الصحف الإكترونيةالتي تمثل عينة

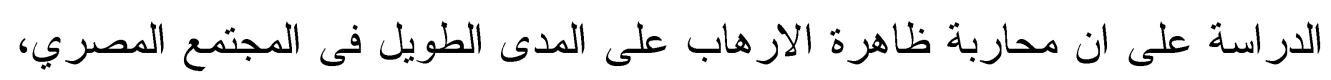

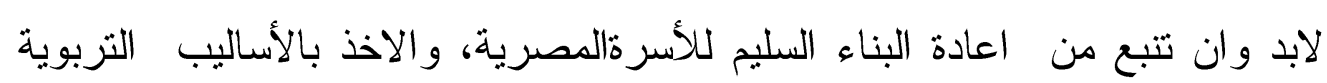
الحديثة للتشئة الاجتماعية للأبناء داخل الاسرة وخارجها، وتوفير فرص حياه

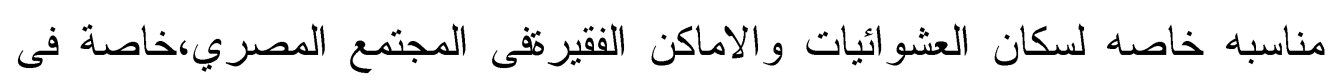
ظل انتشار سرطان العشوائيات ، وما تحمله للمجتمع المصري من مستقبل 


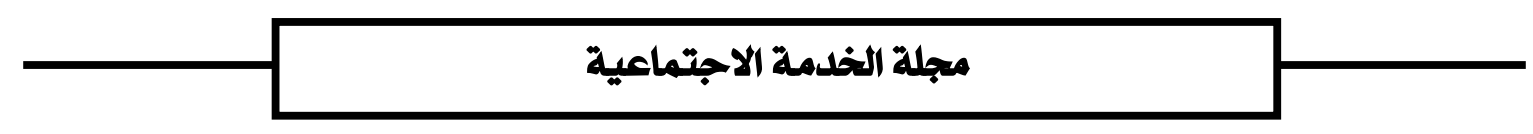

ضبابي ، يكثر فى المشكلات الاجتماعية و الاقتصادية ، خاصة الطى تمس الامن القوم بصورة مباشرة كالإز هاب .

- كثف تحليل المضمون عن حقيقه فحواها ان الصحف الإلكترونية تعتبر من اقل الصحف التي تعرض المقالات التي تتتاول القضايا الهامه، وعلى راسها قضايا الارهاب فى المجتمع المصري ، وتعتمد فى معظمها على التحقيقات و الحو ادثالمصورة،حتى ارتبط ذلك فى ذهن القراء أو متصفحيالاخبار فىهذه الصحف الاكترونية ،حيث يلجئون لتصفح الاخبار، رغبة منهم فى معرفة الحدث بصورة مختصرة ، موضح بالصور . - اوضحت الدر اسة من خلال تحليل مضمون تحقيقات ومقالات الصحف الالكترونية التي تتاولت قضايا الارهاب ، بأنها تتجه لرفض ما بسمى بالإقصاءالاجتماعيو الناتجعن العزل السياسيلأفز اد والجماعات فى المجتمع المصري، وتكاد تتفق على ان الخطوة الاولى لتحجيم ظاهرة الارهاب فى المجتمع هي بتحقيق العدالةالانتقالية، و عدم تعميم سياسات الاقصاء الاجتماعي على كل المنتمين لهذه الجماعات ، وقصر ذلك على من يثبت له دور بأي بشكل فى تعمد الضرر بالمجتمع المصري ، مع الأخذفى الاعتبار خطوات جاده نحو التسويةالسياسية بما يخدم الاهداف العليا للمجتمع المصري. 


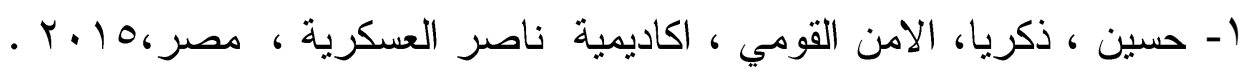

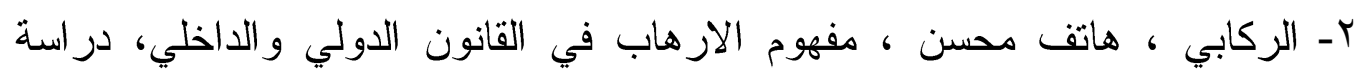

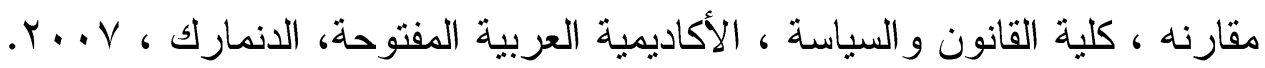
BRUCE HOFFMAN. Inside Terrorism.1998

http://www.nytimes.com/books/first/h/hoffmanterrorism.html

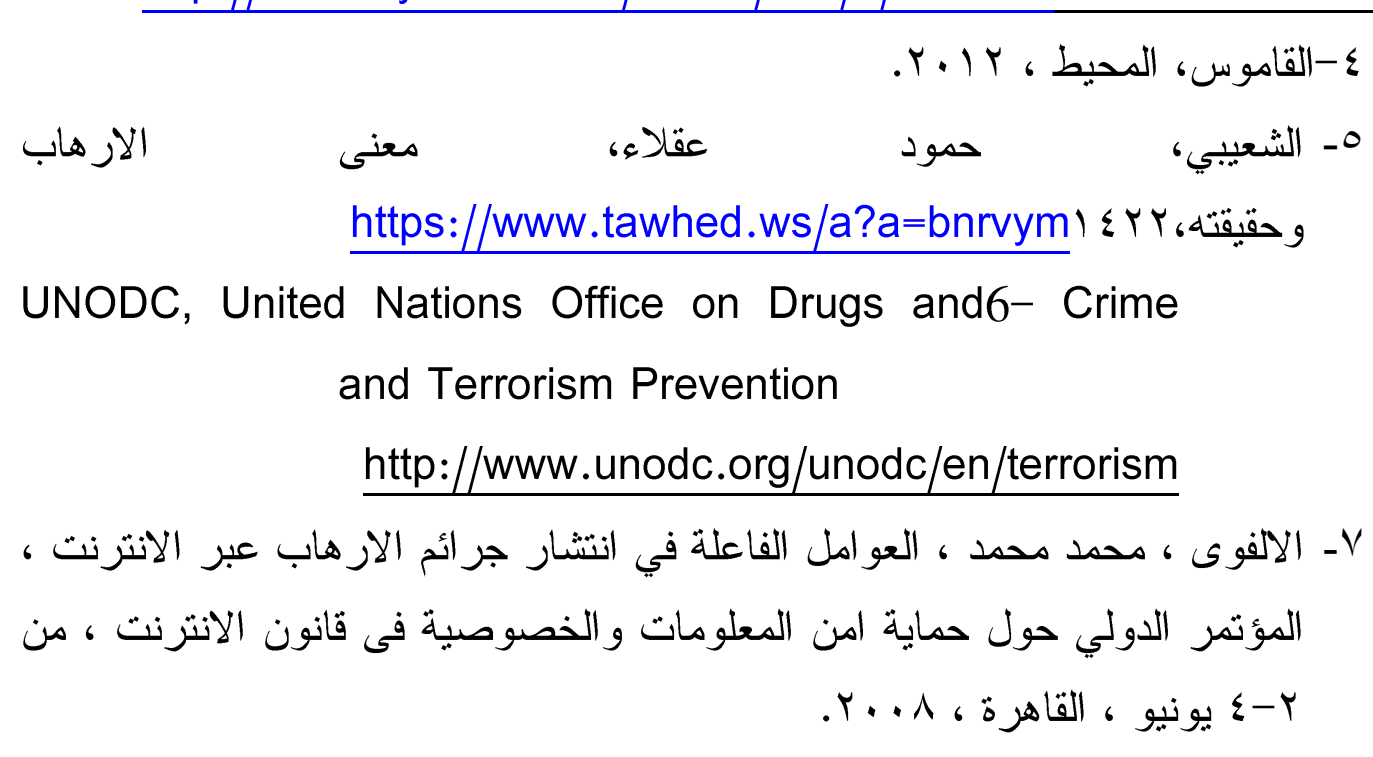

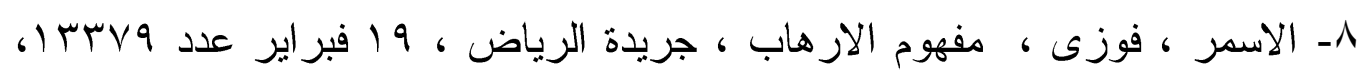

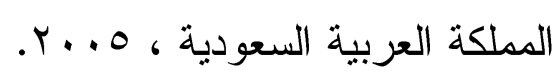

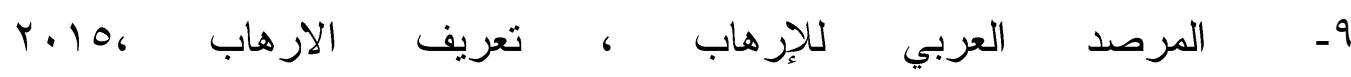
http://arabobservatory.com

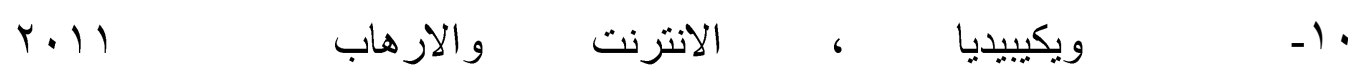
http://ar.wikipedia.org/wik i

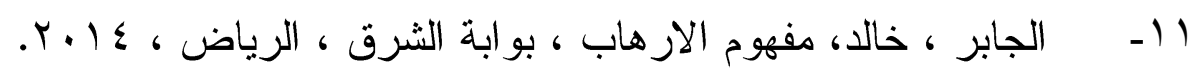
UNODC,2015,Opcit - - Ir

rا- عطا اله ، امام حساسين، الارهاب البنيان القانوني للجريمة ، دار المطبوعات

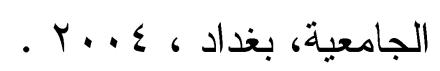

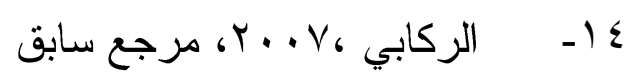

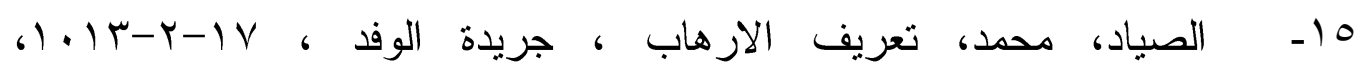

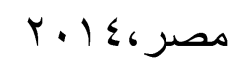

17

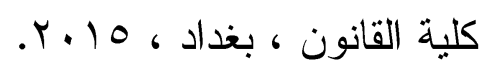




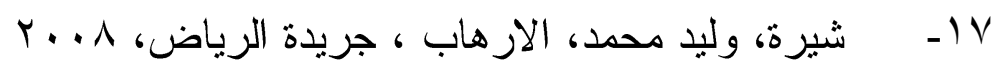

11- الم الدين، محمود، تكنولوجيا الاتصال وصناعة الاتصال الجماهيري،

$$
\text { العربي للنشر و التوزيع، القاهرة، } 9 \text { ـ. . ب. }
$$

9 19 - الغريب، سعيد ، الصحيفة الالكترونية و الورقية ، در اسة مقارنة في المفهوم و السمات الأساسية بالتطبيق على الصحف الاكترونية ، المصرية، المجلة المصرية لبحوث الإعلام ، جامعة القاهرة، كلية الإعلام، (أكتوبر- ديسمبر)، القاهرة $. Y . .16$

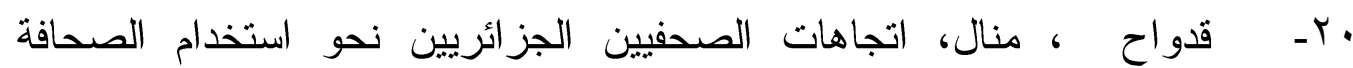
الإلكترونية ، دراسة ميدانية ، رسالة ماجستير بجامعة منتوري، قسنطينة ،

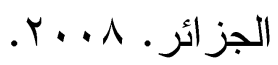

ا - - الرحباني ، عبير شفيق ، استخدامات الصحافة الإلكترونية و وانعكاساتها على الصحف الإلكترونية الأردنية ، رسالة ماجستير بجامعة الشرق الاوسط للار اسات العلبا ، كلية الآداب ، 9 ، . ب.

Y Y - بوثلجي ، الهام ، الصحافة الاكترونية الجزائرية واتجاهات القر اء ، دراسة

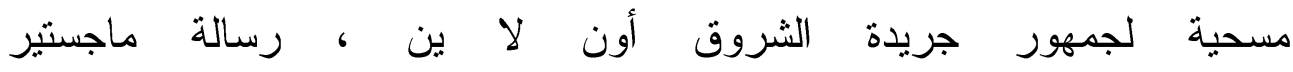

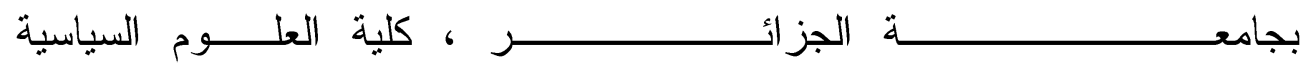

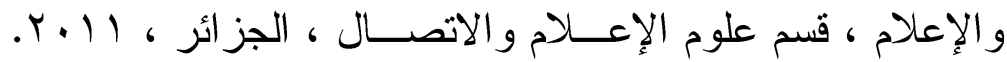
r - غيطاس ،جمال ، ، الصحافة الإلكترونية ، المؤتمر الرابع للصحفيين ، r... www.khayma.com

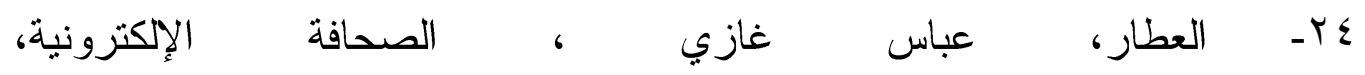

$$
\text { o }
$$

26- Choobineh, J, Trust in electronic commerce:

definition and theoretical considerationsSystem Sciences, M Univ., College Station, TX, USA , 1998

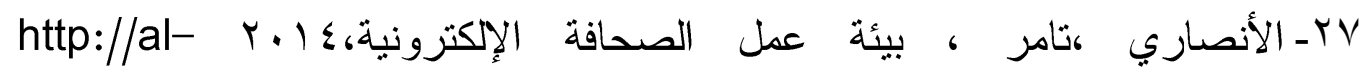
. iraqnews.net/new/studies 


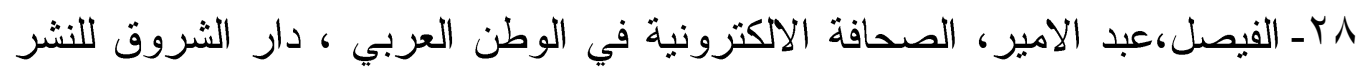

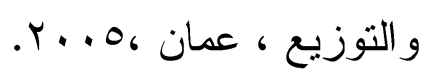

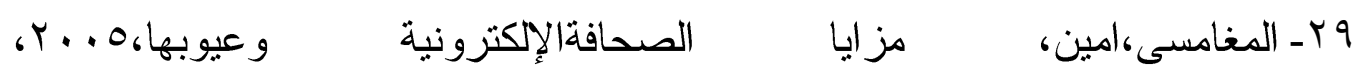

http://almghamsi.blogspot.com.

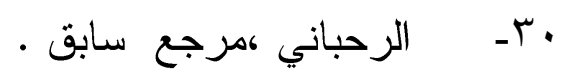

اب- البيد ،هشام زكريا، المعوقات و الصعوبات التي تواجه المواقع الإكترونية

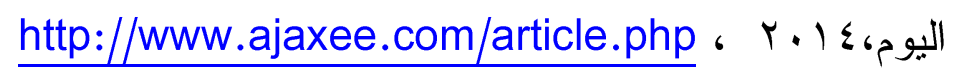

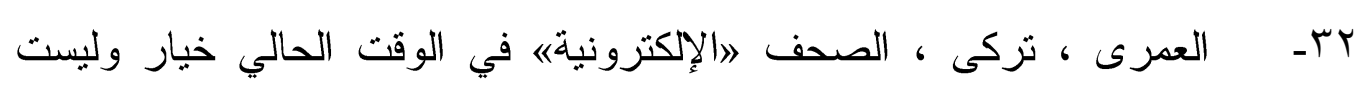

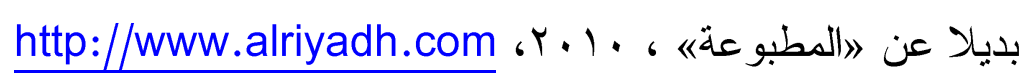

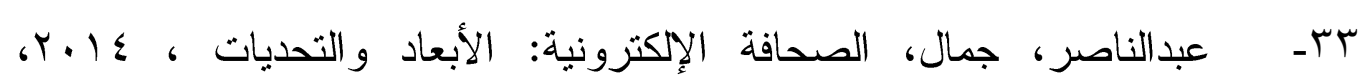
http://www.alukah.net/culture

§ ז- عبد المتعال، أماني، إطلاق الاتحاد العربي للصحافة الإلكترونية بهدف الارتقاء

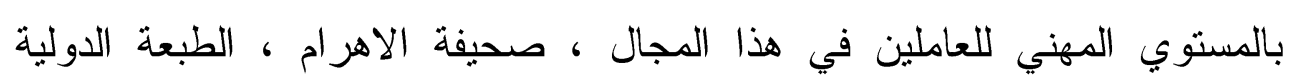
http://digital.ahram.org.eg r.l.

0ب- الخمشى ، ساره صالح، دور التزبية الأسرية فى حماية الابناء من الارهاب

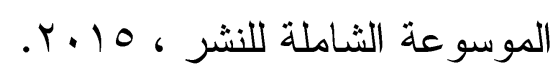

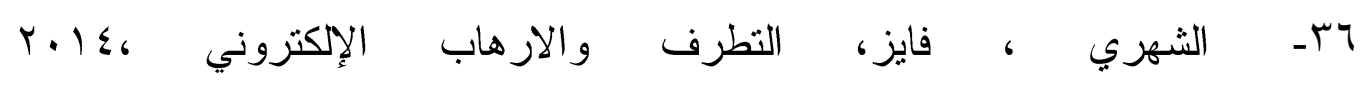
https://www.baareq.com.sa

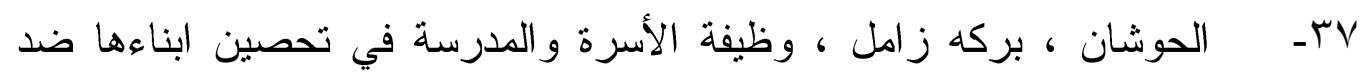

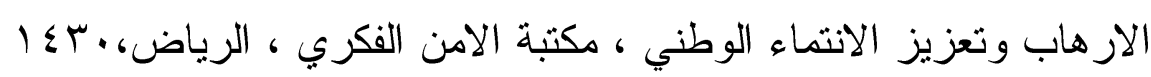

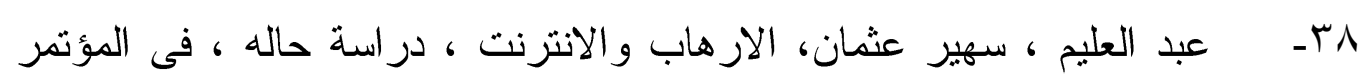

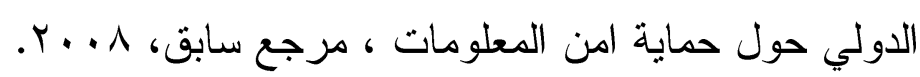
9 بـ الالوفى ، مرجع سابق.

• ــ يوسف ، محمد حامد ، المتغير ات السياسية والاقتصادية و الاجتماعية المرتبطة

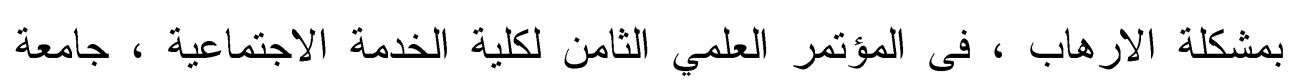

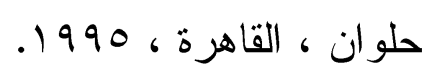

